\title{
Drug Repurposing for Covid-19: Discovery of Potential Small-Molecule Inhibitors of Spike Protein-ACE2 Receptor Interaction Through Virtual Screening and Consensus Scoring
}

Sachin P. Patil ${ }^{1, \S}$, Jeremy Hofer ${ }^{1,2}$, Pedro J. Ballester ${ }^{3}$, Elena Fattakhova ${ }^{1}$, Juliette DiFlumeri ${ }^{1}$, Autumn Campbell ${ }^{1,4}$, Michael Oravic ${ }^{1,4}$

1. NanoBio Laboratory, Department of Chemical Engineering, Widener University, Chester, PA, USA.

2. Department of Computer Science, Widener University, Chester, PA, USA.

3. Cancer Research Center of Marseille (CRCM), INSERM U1068, Marseille, France.

4. Department of Biomedical Engineering, Widener University, Chester, PA, USA.

$\S$ Corresponding address: One University Place, Kirkbride Hall, Chester, Pennsylvania, USA:

Tel.: 1-610-4994492, Fax: 1-610-4994059, Email: spatil\{at\}widener.edu

Running title: Approved drugs against SARS-CoV-2 cellular entry

Key words: Drug repurposing; Covid-19; ACE2; Virtual screening; Protein-protein interaction; Antiviral drugs

Word count: 3,000; Number of references: 50; Number of tables: 3; Number of figures: 2 


\begin{abstract}
Objective

There is an increased interest in drug repurposing against Covid-19 (SARS-CoV-2) as its spread has significantly outpaced development of effective therapeutics. Our aim is to identify approved drugs that can inhibit the interaction of SARS-CoV-2 spike protein with human angiotensinconverting enzyme 2 (ACE2) that is critical for coronavirus infection.
\end{abstract}

\title{
Methods
}

The published crystal structure of SARS-CoV-2 spike protein-ACE2 receptor interaction was first analyzed for druggable binding pockets. The binding interface was then probed by an integrated virtual screening protocol executed by a high-performance computer cluster, involving docking and consensus scoring using various machine-learning, empirical and knowledge-based scoring functions. The consensus-ranked lists of screened drugs were generated via 'rank-byrank' and 'rank-by-number' schemes.

\section{Findings}

Although spike protein and ACE2 lacked druggable pockets in their unbound forms, they presented a well-defined pocket when bound together. Accordingly, we identified many drugs with high binding potential against this protein-protein interaction pocket. Importantly, several antivirals against two major (+)ssRNA viruses (HCV and HIV) constituted major group of our top hits, of which Atazanavir, Grazoprevir, Saquinavir, Simeprevir, Telaprevir and Tipranavir could be of most importance for immediate experimental/clinical investigations. Additional notable hits included many anti-inflammatory/antioxidant, antibiotic/antifungal, and other relevant compounds with proven activity against respiratory diseases, further emphasizing robustness of our current study. Notably, we also discovered Maraviroc, the only FDA-approved drug capable of targeting virus-host interaction and blocking HIV entry.

\section{Conclusion}

Our newly identified compounds warrant further experimental investigation against SARS-CoV2 spike-ACE2 interaction, which if proven effective may present much-needed immediate clinical potential against Covid-19. 


\section{Introduction}

Since detection of the first case of an infection on December 8, 2019, the novel coronavirus 2019 (Covid-19 or SARS-CoV-2) has spread to 213 countries and territories, infecting more than 7 million people worldwide and claiming a staggering 404,396 lives as of June 9, 2020 [1]. This new SARS-CoV-2 coronavirus belongs to the broader coronavirus family comprising total seven known human coronaviruses such as common 229E, HKU1, NL63, OC43 coronaviruses and notorious MERS-CoV (Middle East Respiratory Syndrome) and SARS-CoV (Severe Acute Respiratory Syndrome) coronaviruses [2]. These are enveloped viruses that contain a single positive-stranded RNA and cause a wide variety of respiratory, gastrointestinal and neurological diseases in humans [3]. In comparison to other human coronaviruses, the fatality rate of SARSCoV-2 is relatively low [3]. The transmission rate of SARS-CoV-2, however, is estimated to be significantly higher, infecting first 1,000 patients in merely two days, leading to its declaration as a pandemic by the World Health Organization (WHO) within less than two months of its onset.

Currently there are no FDA-approved drugs available against SARS-CoV-2 as well as SARS$\mathrm{CoV}$ and MERS-CoV, besides the 'exceptional approval' and the 'emergency use authorization' of Remdesivir against SARS-CoV-2 in Japan and the United States, respectively. Thus, there is an unprecedented need to develop effective therapies against these epidemic coronaviruses in general. In this context, several major targets are proposed for SARS-CoV-2 drug discovery such as nonstructural protein 14 and 20 complex (nsp14-nsp20) [4], main protease (Mro), transmembrane protease serine 2 (TMPRSS2) [5] and RNA-dependent RNA polymerase (RdRp) [6], involved in coronavirus RNA replication and transcription process. Another target of therapeutic importance involves protein-protein interaction between coronavirus spike protein receptor-binding domain (RBD) and angiotensin-converting enzyme 2 (ACE2) entry receptor that is central to coronavirus-host interactions. Considering the urgent medical need, the specific drug discovery emphasis is on repurposing already approved drugs against these targets, which may present immediate clinical potential against this global health emergency. In this regard, several approved drugs including Remdesivir (RdRp inhibitor), Lopinavir/Ritonavir (antiviral drugs), Camostat (TMPRSS2 inhibitor), as well as Chloroquine/Hydroxychloroquine (antimalarials) and Azithromycin (antibiotic) are currently undergoing clinical trials to determine whether they offer sufficient benefits as anti-Covid-19 agents. In addition, numerous studies have been published so far reporting other promising compounds against Covid-19 identified by different computational and high throughput approaches [7-10].

In this study, we present computational investigation of drugs approved in at least one jurisdiction worldwide for their potential utility against the SARS-CoV-2 viral uptake through ACE2 interaction. Specifically, total 91 approved drugs are identified as putative agents against SARS-CoV-2 through their potential role in inhibiting the SARS-CoV-2 spike protein-ACE2 receptor interaction. These drugs, if experimentally validated to inhibit this pathological proteinprotein interaction, may present immediate repurposing opportunity for Covid-19 treatment and thus warrant further characterization and development by broader scientific community. 


\section{Materials and Methods}

\section{Virtual screening with AutoDock Vina}

The crystal structure of the SARS-CoV-2 spike protein receptor-binding domain bound with the human ACE2 entry receptor (PDB ID: 6M0J, resolution 2.45 $\AA$ ) was downloaded from the protein data bank (PDB) and processed using the AutoDock Tools utility [11]. The two chains were then investigated both individually and in their bound form for potential druggable pockets and sub-pockets using DoGSiteScorer web server [12]. The approved drug subset downloaded from ZINC15 database [13] was used for the virtual screening against these appropriate protein binding pockets $(3,278$ drugs approved in major jurisdictions worldwide). Owing to the multiple potential structural entries associated with each ligand in ZINC databases, there were total 5,587 ZINC ligand entries in this database. The ligand and protein atoms were converted into PDBQT format. The AutoDock Vina docking algorithm was then used to carry out structure-based docking of these drug molecules to the spike-ACE2 binding interface. Default docking parameters were used and the docked ligands were ranked according to their best docking score values.

\section{Consensus scoring}

To decrease the potential false positives and thus increase the hit rate, the best docked conformer of each compound was further reevaluated with multiple scoring functions, viz. DSX (knowledge-based), X-Score (empirical), and NNScore and RF-Score-VS (machine-learning) [14-18]. To create a consensus-ranked list of the screened drug molecules across five scoring functions, the best score associated with a given scoring function was used for each ligand via 'rank-by-rank' and also 'rank-by-number' schemes [19]. The rank-by-rank method is straightforward, whereby the consensus rank of each ligand is an average of the rank values from the individual scoring functions. In contrast, in the rank-by-number scheme the binding scores of each scoring function were first scaled to unit variance and centered, as described previously [20]. The consensus score for each ligand is then determined by taking average of scaled scores across the 5 individual scoring functions mentioned above. We implemented automated scripts on a high-performance parallel computing cluster to carry out all these virtual screening and scoring analyses.

\section{Molecular dynamics}

To investigate potential molecular interactions of the top hits within the target pocket, their topranked vina docking complexes were subjected to the post-docking structural optimization using the default relaxation protocol in the Desmond Molecular Dynamics package. The relaxation protocol included two stages of minimization (restrained and unrestrained) followed by four stages of short molecular dynamics runs with gradually diminishing restraints and increasing temperature. The optimized ligand-protein complex structures were visually inspected using Schrodinger's Maestro GUI, for complementarity to the binding site and interactions with surrounding amino acid residues. 


\section{Results and Discussion}

The human infections by SARS coronaviruses including CoV-2 are caused by the interactions of the viral spike proteins with the receptors expressed on human cells viz. the Angiotensin Converting Enzyme 2 (ACE2) [21]. ACE2 is expressed on lung, heart, kidney, testis and gut cell membranes [22]. ACE2 being the critical gatekeeper of viral entry into different human cells, this spike-ACE2 interaction represents one of the most important therapeutic targets for the development of drugs and vaccines against coronaviruses [23]. It should be noted that ACE2 is critical not only for viral entry into the cell and replication, but also important for defense against heart and lung injury [24]. Thus, inhibitors of ACE2 enzymatic activity could potentially worsen the ability of the lung to defend itself from damage caused by the virus. In contrast, we wish to report here the discovery of approved drugs as putative small-molecule inhibitors of spike-ACE2 protein-protein interaction, through structure-based virtual screening followed by consensus scoring. Such inhibitors of this pathological protein-protein interaction may prove highly effective against Covid-19 through limiting the coronavirus entry and infection of the host cells.

Although some computational drug repurposing studies against this challenging target have been published so far, most of them utilized homology models of these proteins owing to the lack of experimental structure at that time [25-29]. In contrast, our virtual screening approach utilized the most recent X-ray crystal structure of SARS-CoV-2 spike receptor-binding domain bound with the human ACE2 entry receptor [30]. This high-resolution X-ray structure offers the closest representation of the atomic level understanding towards the initial step of infection by SARS$\mathrm{CoV}-2$ coronavirus. As the spike protein is considered to be central to promoting host attachment and protein-mediated membrane fusion of the virus, blocking its receptor-binding domain by a ligand may provide an effective way to inhibit its entry into human cells.

In this context, we first explored the human ACE2 interaction domain on the isolated SARS$\mathrm{CoV}-2$ spike protein receptor-binding domain to identify any potential druggable pockets suitable to bind such small-molecule ligands, using DoGSiteScorer server [12]. Unfortunately, the ACE2 interaction domain on SARS-CoV-2 spike protein completely lacked such druggable binding pockets, thus rendering it to be unsuitable for virtual screening efforts. This was also the case with the isolated ACE2 protein interface where spike protein receptor-binding domain binds. The observed lack of any druggable binding pockets on these two proteins at their individual binding surfaces should be taken into account when analyzing the data from previous studies that carried out docking against them separately [26-29, 31-33]. In contrast, these binding partners in their bound form presented a well-defined binding pocket with the DoGSiteScorer druggability score of 0.71 , thus offering an induced binding cleft that is optimum for binding putative small-molecule modulators of this important protein-protein interaction (Figure 1). We hypothesize that such interface-binding molecules, especially those with potential to exert disproportionate interaction affinity towards one protein partner over another, may prove effective in destabilizing the host-virus interactions.

Therefore, with the aim of discovering such small-molecule inhibitors targeting this spike-ACE2 interface pocket, we docked $~ 5,587$ approved drugs into this pocket using the Autodock Vina algorithm. The top docking hits showed good binding scores to the spike-ACE2 interface pocket, with the best score being $-11.1 \mathrm{Kcal} / \mathrm{mol}$ for ZINC72206342. Although these promising 
AutoDock Vina scores further support druggability of this targeted pocket as assessed by the DoGSiteScorer algorithm, it should be noted that Vina scoring function has $\sim 2.85 \mathrm{Kcal} / \mathrm{mol}$ standard error [34]. This is a general limitation associated with all available scoring functions to a varying degree, making use of any one of them individually prone to enriching the false positives in a given virtual screening campaign.

Therefore, we utilized consensuses scoring approaches, whereby multiple scoring functions are applied to re-score and re-rank the best docked conformer of each of the docked ligands. Such consensus scoring approach has been shown to be more robust and accurate than any single scoring procedure, thus leading to significant improvement of the hit rates in virtual library screening [19]. Importantly, consensus scoring has been shown to be independent of the target receptor under consideration, the docking method used, and also the scoring functions applied. Also, use of even a moderately small number of scoring functions (three or four) is shown to be sufficient to improve the screening results significantly. Thus, in addition to default AutoDock Vina, we used four additional scoring functions spanning knowledge-based (DSX), empirical (XScore) and machine-learning scoring functions (NNScore and RF-Score-VS) [14-18]. We then combined these data from multiple scoring functions using the rank-by-rank and rank-by-number strategies, in an effort to enrich the virtual screening hit list [20]. The consensus hit lists containing top 100 each of the approved drugs thus obtained by these two ranking schemes are presented in Tables 1 and 2. As can be seen, many of the drugs are common to both lists.

We then combined these two sets of data, leading to a final consensus hit list that contained total 141 ZINC ligand entries representing 91 unique approved drug molecules (Table 3). When grouped according to their action mechanism or target, the known antivirals were identified to be the most prominent group of our hit list (total 14 antiviral drugs). This is very promising and in line with a recently published comprehensive analysis that showed antivirals together with antibiotics and corticosteroids were the most frequently administered drug classes to the first 9,152 reported cases of Covid-19 [35]. The antivirals discovered here included approved drugs against two other major enveloped (+) ssRNA viruses, viz. HIV (Atazanavir, Cobicistat, Indinavir, Saquinavir and Tipranavir) and HCV (Asunaprevir, Daclatasvir, Elbasvir, Glecaprevir, Grazoprevir, Ombitasvir, Simeprevir, Telaprevir, Voxilaprevir), further supporting their potential use to treat Covid-19. Notably, all four ZINC database structure entries for Saquinavir were short-listed as the top hits against this protein-protein interaction target. It is noteworthy that majority of our identified drugs are novel suggestions against Covid-19. In comparison, other antiviral drugs studied against Covid-19 previously included Acyclovir, Darunavir, Favipiravir, Ganciclovir, Lopinavir-Ritonavir combination, Oseltamivir, Remdesivir, Ribavarin and Umifenovir [36-38]. Thus, our newly identified antiviral drugs warrant urgent addition to the arsenal for in vitro testing against Covid-19.

In addition to these antiviral drugs, other major groups of compounds identified here as potential inhibitors of spike protein-ACE2 receptor interaction involved several antiinflammatory/antioxidant $(\sim 14 \%)$, antibiotic/antifungal $(\sim 13 \%)$, anticancer $(\sim 15 \%)$, anticonvulsant/antipsychotic $(\sim 5 \%)$, and antihypertensive $(\sim 4 \%)$ drugs. Although our innate immune system is vital in controlling the replication and infection of coronavirus [26], overactivated immune system leads to inflammatory cytokine storm in many patients, resulting in fatal collateral tissue damage [39]. Thus, anti-inflammatory and antioxidant drugs identified in 
the present study may prove helpful against overactivated immune response observed in Covid19 patients. In this context, clinical trials are ongoing to test efficacy of various immunosuppressant drugs against Covid-19, including two specific IL-6 inhibitors, viz. Tocilizumab by Roche and Sarilumab by Regeneron. Notably, one of our top hits is Everolimus, which is an effective macrolide immunosuppressant drug.

Furthermore, several antibiotic and antifungal drugs we discovered here may prove effective against Covid-19. A macrolide antibiotic Azithromycin is already being investigated against Covid-19 owing to its excellent activity in inhibiting viral replication in vitro [40]. Interestingly, one of our antibiotic hits Telithromycin has been proven to be effective against communityacquired pneumonia caused by streptococcus pneumoniae [41], indicting potential application to treat coronavirus pneumonia. Also, two of our top antifungal hits Itraconazole and Posaconazole, are known to be effective in treating lung infections [42]. Moreover, three anticonvulsant drugs we discovered are metabolites of Valproate, which is currently being investigated against Covid19 owing to its anti-inflammatory and intrinsic antiviral properties [43].

Three antiparasitic drugs also appeared in our hit list, viz. Ivermectin, Spinosad and Voacamine. Spinosad is an effective, natural product-based insecticide used to treat head lice and has low mammalian toxicity. Voacamine is approved for use as an antimalarial drug in many countries worldwide. Furthermore, Ivermectin is an approved drug with nuclear transport inhibitory activity that has been shown to be effective in significantly inhibiting Covid-19 virus replication in vitro [44].

Antitumor drugs also formed a major group of our hit list, including several chemotherapeutics, a proteasome inhibitor Carfilzomib and three selective tyrosine kinase inhibitors, viz. AFN911 (a metabolite of Imatinib), Brigatinib and Ponatinib. It is noteworthy that Imatinib has previously been demonstrated to inhibit both SARS-CoV and MERS-CoV replication in vitro [45]. Interestingly, Imatinib was shown to specifically interfere with SARS-CoV spike proteininduced membrane fusion of virus with host cells [46]. Taken together, our current data may suggest similar activity against SARS-CoV-2 also, through potential inhibition of spike proteinACE2 receptor interaction, as shown in the present study.

Antihypertensives are another group of drugs we identified as top hits that are of direct relevance to Covid-19. These include angiotensin-converting enzyme/ACE inhibitors (Fosinopril and Reserpinin) and angiotensin receptor blockers/ARBs (Candesartan and Saralasin). Such inhibitors of renin-angiotensin-aldosterone system (RAAS) were initially thought to be contraindicative in Covid-19, owing to their potential role in possibly increasing the ACE2 levels that may aid in SARS-CoV-2 viral entry into host cells [47]. This is, however, largely based on preclinical studies, and the human clinical data in support of this is clearly lacking. In contrast, ACE2 is known to offer protection against cardio and lung injury, and SARS-CoV-2 is actually found to downregulate ACE2 expression after exploiting it for cell entry [47]. In this context, clinical trials are ongoing to test the efficacy of ACE2 restoration against Covid-19 through administration of RAAS modulators, including recombinant ACE2 and the ARB Losartan (ClinicalTrials.gov IDs: NCT04287686, NCT04312009, NCT04311177). Here, it is noteworthy that the RAAS inhibitors identified in our present study may prove to be dually beneficial against Covid-19 by not only increasing the expression of lung- and cardio-protective ACE2, but also 
simultaneously blocking its interaction with SARS-CoV-2 spike protein as indicated by our in silico data.

Other promising drugs identified here included antihistamines (Astemizole, Ternadin), antipsychotics (Aripiprazole, Pipotiazine), leukotriene receptor antagonists (Montelukast, Zafirlukast), pulmonary surfactants (Palmitoyloleoyl-phosphatidylglycerol, Colfosceril palmitate), a chemokine receptor antagonist (Maraviroc), an antithrombotic (Vorapaxar), and a cardiac glycoside (Digoxigenin bisdigitoxoside). Out of these, Astemizole has been shown to significantly inhibit replication of SARS-CoV-2 as well as MERS-CoV and SARS-CoV [45, 48], while Pioptiazine is structurally similar to another phenothiazine antipsychotic drug Chlorpromazine that is active against MERS-CoV and SARS-CoV [48]. Also, Motelukast and Zafirlukast are approved for treating chronic obstructive pulmonary disease. Furthermore, pulmonary surfactants Colfosceril palmitate and Palmitoyloleoyl-phosphatidylglycerol are beneficial in patients with respiratory distress syndrome [49]. Importantly, another of our top compound Maraviroc is the only FDA-approved drug of its kind that is known to target virushost interaction and human cell entry, through blocking interaction of HIV-1 gp120 protein with CCR5 expressed on T-cells [36]. To the best of our knowledge, our study is the first to indicate possible use of Maraviroc against SARS-CoV-2 cell entry through potential inhibition of spike protein-ACE2 receptor interaction.

To investigate potential molecular interactions of our top hits at the spike-ACE2 binding interface, their top-ranked docking complexes were subjected to the post-docking optimization. The optimized ligand-protein complex structures thus obtained for 20 most promising drugs are shown in Figure 2. As expected, reasonable binding poses were found in all cases, demonstrating that these drugs fit inside the binding pocket well. As can be seen, these compounds made multiple interactions with several amino acid residues near the binding pocket on both binding proteins. By making these key hydrogen bonding and hydrophobic interactions at the binding interface, these molecules may efficiently inhibit the spike protein-mediated fusion of the virus with the host cell membrane, leading in turn to blocking the first step of viral infection in terms of viral cell entry.

\section{Conclusions}

In summary, we have described a successful structure-based discovery of several approved drugs as potential inhibitors of spike protein-ACE2 receptor interaction. In addition to inhibition of viral host entry through blocking this critical protein-protein interaction, the primary inherent pharmacological actions of our newly discovered drugs may provide additional therapeutic avenues for treating viral infection-associated pneumonia, inflammation and oxidative damage. Some of these drugs are also suggested to bind to other important Covid-19 targets. For example, Atazanavir and Saquinavir are predicted to bind to coronavirus main protease $\mathrm{M}_{\text {Pro }}[9,28,50]$, while Itraconazole is predicted to bind to RdRp, another important target involved in viral RNA synthesis and replication [26]. Such multi-targeting drugs may not only increase the therapeutic efficacy, but also significantly decrease the possibility of drug resistance development by this highly infectious disease. Therefore, we wish to make these readily available compounds public here, with the aim of facilitating their urgent in vitro evaluations leading to rapid clinical development of effective drugs against Covid-19. 


\section{Acknowledgements}

We thank Dr. Jeffrey Rufinus and John Stoddart for access to the high-performance computer cluster in the Department of Computer Science at Widener University.

\section{Conflicts of interest}

The authors declare no conflict of interest. 


\section{References}

1. WHO Coronavirus Disease (COVID-19) Dashboard. https://covid19.who.int

2. CDC |SARS | Basics Factsheet | Centers for Disease Control and Prevention. https://www.cdc.gov/sars/about/fs-sars.html

3. Petrosillo N, Viceconte G, et al (2020) COVID-19, SARS and MERS: are they closely related? Clin Microbiol Infect 26(6): 729-734. DOI: 10.1016/j.cmi.2020.03.026

4. $\mathrm{Ma} \mathrm{Y}, \mathrm{Wu} \mathrm{L}$, et al (2015) Structure of SARS coronavirus nsp14-nsp10 complex. Proc Natl Acad Sci U S A. 112(30): 9436-9441. DOI:10.1073/pnas.1508686112

5. Hoffmann M, Kleine-Weber H, et al (2020) SARS-CoV-2 Cell Entry Depends on ACE2 and TMPRSS2 and Is Blocked by a Clinically Proven Protease Inhibitor. Cell 181(2): 271-280.e8. DOI:10.1016/j.cell.2020.02.052

6. Smith E C, Blanc H, et al (2013) Coronaviruses Lacking Exoribonuclease Activity Are Susceptible to Lethal Mutagenesis: Evidence for Proofreading and Potential Therapeutics. PLoS Pathogens 9(8): e1003565. DOI:10.1371/journal.ppat.1003565

7. Ton A-T, Gentile F, et al (2020) Rapid Identification of Potential Inhibitors of SARSCoV-2 Main Protease by Deep Docking of 1.3 Billion Compounds. Molecular Inform 39: 1-18. DOI:10.1002/minf.202000028

8. Zhang D-H, Wu K-L, et al (2020) In silico screening of Chinese herbal medicines with the potential to directly inhibit 2019 novel coronavirus. J Integr Med 18(2): 152-158. DOI:https://doi.org/10.1016/j.joim.2020.02.005

9. Ekins S, Mottin M, et al (2020) Deja vu: Stimulating Open Drug Discovery For SARSCoV-2. Drug Discov Today, In Press-Corrected Proof.

DOI:https://doi.org/10.1016/j.drudis.2020.03.019

10. Ge Y, Tian T, et al (2020) A data-driven drug repositioning framework discovered a potential therapeutic agent targeting COVID-19. bioRxiv Preprint.

DOI:https://doi.org/10.1101/2020.03.11.986836

11. Morris G M, Huey R, et al (2009) AutoDock4 and AutoDockTools4: Automated Docking With Selective Receptor Flexibility. J. Comput. Chem 30(16): 2785-2791.

DOI:10.1002/jcc.21256

12. Volkamer A, Kuhn D, et al (2012) DoGSiteScorer: a web server for automatic binding site prediction, analysis and druggability assessment. Bioinformatics 28(15): 2074-2075. DOI:https://doi.org/10.1093/bioinformatics/bts310

13. Sterling T, Irwin J J (2015) ZINC 15 - Ligand Discovery for Everyone. J Chem Inf Model (55): 2324-2337. DOI:doi.org/10.1021/acs.jcim.5b00559

14. Wójcikowski M, Ballester P J, Siedlecki P (2017) Performance of machine-learning scoring functions in structure-based virtual screening. Sci Rep 7: 46710. DOI:10.1038/srep46710 (2017)

15. Fresnais L, Ballester P J (2020) The impact of compound library size on the performance of scoring functions for structure-based virtual screening. bioRxiv Preprint. DOI: https://doi.org/10.1101/2020.03.18.997411

16. Durrant J D, McCammon J A (2011) NNScore 2.0: A Neural-Network Receptor-Ligand Scoring Function. J Chem Inf Model 51(11): 2897-2903. DOI:10.1021/ci2003889

17. Wang R, Lai L, Wang S (2002) Further development and validation of empirical scoring functions for structure-based binding affinity prediction. J Comput Aided Mol Des 16(1): 11-26. DOI:10.1023/a:1016357811882 
18. Neudert G, Klebe G (2011) DSX: A Knowledge-Based Scoring Function for the Assessment of Protein-Ligand Complexes. J Chem Inf Model 51(10): 2731-2745. DOI:10.1021/ci200274q

19. Wang R, Wang S (2001) How Does Consensus Scoring Work for Virtual Library Screening? An Idealized Computer Experiment. J Chem Inf Comput Sci 41(5): 14221426. DOI:https://doi.org/10.1021/ci010025x

20. Liu S, Fu R, et al (2012) Application of Consensus Scoring and Principal Component Analysis for Virtual Screening against $\beta$-Secretase (BACE-1). PLoS One 7(6): e38086. DOI:10.1371/journal.pone.0038086

21. Wrapp D, Wang N, et al (2020) Cryo-EM structure of the 2019-nCoV spike in the prefusion conformation. Science 367(6483): 1260-1263. DOI:10.1126/science.abb2507

22. Perlot T, Penninger J M (2013) ACE2 - from the renin-angiotensin system to gut microbiota and malnutrition. Microbes Infect 15(13): 866-873. DOI:10.1016/j.micinf.2013.08.003

23. Du L, Yang Y, et al (2017) MERS-CoV spike protein: a key target for antivirals. Expert Opin Ther Targets 21(2): 131-143. DOI:10.1080/14728222.2017.1271415

24. Zhang H, Penninger J M, et al (2020) Angiotensin-converting enzyme 2 (ACE2) as a SARS-CoV-2 receptor: molecular mechanisms and potential therapeutic target. Intensive Care Med 46(4): 586-590. DOI:10.1007/s00134-020-05985-9

25. Smith M, Smith J C (2020) Repurposing Therapeutics for COVID-19: SupercomputerBased Docking to the SARS-CoV-2 Viral Spike Protein and Viral Spike Protein-Human ACE2 Interface. ChemRxiv Preprint. DOI:https://doi.org/10.26434/chemrxiv.11871402.v4

26. Wu C, Liu Y, et al (2020) Analysis of therapeutic targets for SARS-CoV-2 and discovery of potential drugs by computational methods. Acta Pharmaceutica Sinica B 10(5): 766788. DOI:https://doi.org/10.1016/j.apsb.2020.02.008

27. Abdel-Mottaleb M S A, Abdel-Mottaleb Y (2020) In Search for Effective and Safe Drugs against SARS-CoV-2: [Part I] Simulated interactions between selected nutraceuticals, ACE2 enzyme and S Protein simple peptide sequences. ChemRxiv Preprint. DOI:doi.org/10.26434/chemrxiv.12155235.v1

28. Kadioglu O, Saeed M, et al (2020) Identification of novel compounds against three targets of SARS CoV-2 coronavirus by combined virtual screening and supervised machine learning. Bull World Health Organ Preprint DOI:http://dx.doi.org/10.2471/BLT.20.255943

29. Hall Jr D C, Ji H-F (2020) A search for medications to treat COVID-19 via in silico molecular docking models of the SARS-CoV-2 spike glycoprotein and 3CL protease. Travel Med Infect Dis. DOI:https://doi.org/10.1016/j.tmaid.2020.101646

30. Lan J, Ge J, et al (2020) Structure of the SARS-CoV-2 spike receptor-binding domain bound to the ACE2 receptor. Nature 581(7807): 215-220. DOI:10.1038/s41586-0202180-5

31. Chen H, Du Q (2020) Potential Natural Compounds for Preventing SARS-CoV-2 (2019nCoV) Infection. Preprints, 2020010358. DOI:10.20944/preprints202001.0358.v3.

32. Saadat S, Mansoor S, et al (2020) Structure based drug discovery by virtual screening of 3699 compounds against the crystal structures of six key SARS-CoV-2 proteins. Preprint from Research Square. DOI:10.21203/rs.3.rs-28113/v1 
33. Sharp K, Dr. Dange S (2020) In silico FDA-approved drug repurposing to find the possible treatment of Coronavirus Disease -19 (COVID-19). ChemRxiv Preprint. DOI:https://doi.org/10.26434/chemrxiv.12129129

34. Trott O, Olson A J (2010) AutoDock Vina: improving the speed and accuracy of docking with a new scoring function, efficient optimization, and multithreading. J Comput Chem 31(2): 455-461. DOI:10.1002/jcc.21334

35. Fajgenbaum D C, Khor J S et al (2020) Treatments administered to the first 9,152 reported cases of COVID19: a systematic review. medRxiv Preprint. DOI:https://doi.org/10.1101/2020.05.07.20073981

36. Li G, de Clercq E (2020) Therapeutic options for the 2019 novel coronavirus (2019nCoV). Nat Rev Drug Discov 19(3): 149-150. DOI:10.1038/d41573-020-00016-0

37. Cao B, Wang Y, et al (2020) A Trial of Lopinavir-Ritonavir in Adults Hospitalized with Severe Covid-19. N Engl J Med 382: 1787-1799. DOI:10.1056/NEJMoa2001282

38. Wang D, Hu B, et al (2020) Clinical Characteristics of 138 Hospitalized Patients With 2019 Novel Coronavirus-Infected Pneumonia in Wuhan, China. JAMA 323(11): 10611069. DOI:10.1001/jama.2020.1585

39. Mahmudpoura M, Roozbehb J, at al (2020) COVID-19 cytokine storm: The anger of inflammation. Cytokine. In Press, Journal Pre-proof. 155151.

DOI:https://doi.org/10.1016/j.cyto.2020.155151

40. Touret F, Gilles M, at al (2020) In vitro screening of a FDA approved chemical library reveals potential inhibitors of SARS-CoV-2 replication. bioRxiv Preprint. DOI:https://doi.org/10.1101/2020.04.03.023846

41. Tran M P (2004) Telithromycin: a novel agent for the treatment of community-acquired upper respiratory infections. Proc (Bayl Univ Med Cent) 17(4): 475-479. DOI:10.1080/08998280.2004.11928017

42. Maturu V N, Agarwal R (2015) Itraconazole in chronic pulmonary aspergillosis: In whom, for how long, and at what dose? Lung India 32(4): 309-312. DOI:https://doi.org/10.4103/0970-2113.159523

43. Chiquete E, Toapanta-Yanchapaxi L, Cantu-Brito C (2020) Methods of An Open-Label Proof-Of-Concept Trial of Intravenous Valproic Acid for Severe COVID-19. medRxiv Preprint. DOI:https://doi.org/10.1101/2020.04.26.20079988

44. Calya L, Drucea J D, et al (2020) The FDA-approved drug ivermectin inhibits the replication of SARS-CoV-2 in vitro. Antiviral Res 178:104787.

DOI:https://doi.org/10.1016/j.antiviral.2020.104787

45. Coleman C M, Dyall J, et al (2014) Repurposing of Clinically Developed Drugs for Treatment of Middle East Respiratory Syndrome Coronavirus Infection. Antimicrob Agents Chemother 58(8): 4885-4893. DOI:10.1128/AAC.03036-14

46. Sisk J M, Frieman M B, et al (2018) Coronavirus S Protein-Induced Fusion Is Blocked Prior to Hemifusion by Abl Kinase Inhibitors. J Gen Virol 99(5): 619-630. DOI:10.1099/jgv.0.001047.

47. Vaduganathan M, Vardeny O, et al (2020) Renin-Angiotensin-Aldosterone System Inhibitors in Patients with Covid-19. N Engl J Med 382: 1653-1659.

DOI:10.1056/NEJMsr2005760

48. Riva L, Yuan S, et al (2020) A Large-scale Drug Repositioning Survey for SARS-CoV-2 Antivirals. bioRxiv Preprint. DOI:https://doi.org/10.1101/2020.04.16.044016 
49. Bryson H M, Whittington R (1994) Colfosceril palmitate. A pharmacoeconomic evaluation of a synthetic surfactant preparation (Exosurf Neonatal) in infants with respiratory distress syndrome. Pharmacoeconomics 6(6): 563-577.

DOI:10.2165/00019053-199406060-00009

50. Bobrowski T, Alves V, et al (2020) Computational Models Identify Several FDA Approved or Experimental Drugs as Putative Agents Against SARS-CoV-2. ChemRxiv Preprint. DOI:https://doi.org/10.26434/chemrxiv.12153594.v1 
Table 1. Top 100 hits from a database of approved drugs, as identified by rank-by-rank consensus scoring scheme utilizing five different scoring functions.

\begin{tabular}{|c|c|c|}
\hline Rank & ZINC ID & Name \\
\hline 1 & 11677911 & Bisoctrizole \\
\hline 2 & 3914596 & Saquinavir \\
\hline 3 & 150588351 & Elbasvir \\
\hline 4 & 72190231 & Posaconazole \\
\hline 5 & 26664090 & Saquinavir \\
\hline 6 & 29416466 & Saquinavir \\
\hline 7 & 27990463 & Lomitapide \\
\hline 8 & 169621210 & Voacamine \\
\hline 9 & 11677894 & Bemotrizinol \\
\hline 10 & 26985532 & Saquinavir \\
\hline 11 & 150601177 & Ombitasvir \\
\hline 12 & 100022637 & Tipranavir \\
\hline 13 & 100016058 & Tipranavir \\
\hline 14 & 253387884 & Hydroxyitraconazole \\
\hline 15 & 60392779 & Posaconazole \\
\hline 16 & 8214644 & Pentagastrin \\
\hline 17 & 22448696 & Indinavir \\
\hline 18 & 49841054 & Carfilzomib \\
\hline 19 & 218037687 & Voxilaprevir \\
\hline 20 & 96006020 & Paclitaxel \\
\hline 21 & 17653971 & Canthaxanthin \\
\hline 22 & 28639340 & Posaconazole \\
\hline 23 & 164528615 & Glecaprevir \\
\hline 24 & 238809663 & Atracurium besylate \\
\hline 25 & 6845076 & B-Carotene \\
\hline 26 & 4097427 & Candesartan \\
\hline 27 & 3938482 & Posaconazole \\
\hline 28 & 49918329 & Valrubicin \\
\hline 29 & 253632968 & Simeprevir \\
\hline 30 & 164760756 & Simeprevir \\
\hline 31 & 95618745 & RPR123142 \\
\hline 32 & 95618746 & RPR123142 \\
\hline 33 & 150339320 & Hydroxyitraconazole \\
\hline 34 & 169621209 & Voacamine \\
\hline
\end{tabular}

\begin{tabular}{|c|c|c|}
\hline Rank & ZINC ID & Name \\
\hline 35 & 896717 & Zafirlukast \\
\hline 36 & 3941496 & Atazanavir \\
\hline 37 & 150339325 & Hydroxyitraconazole \\
\hline 38 & 49783788 & Valrubicin \\
\hline 39 & 4074875 & Candesartan \\
\hline 40 & 150339328 & Hydroxyitraconazole \\
\hline 41 & 68204830 & Daclatasvir \\
\hline 42 & 3934128 & Temoporfin \\
\hline 43 & 85536932 & Cabazitaxel \\
\hline 44 & 95551509 & Grazoprevir \\
\hline 45 & 95617640 & Imatinib metabolite \\
\hline 46 & 936069565 & Glecaprevir \\
\hline 47 & 72131401 & Hydroxyitraconazole \\
\hline 48 & 4097344 & Itraconazole \\
\hline 49 & 118915215 & $\begin{array}{l}\text { Digoxigenin } \\
\text { bisdigitoxoside }\end{array}$ \\
\hline 50 & 118915214 & $\begin{array}{l}\text { Digoxigenin } \\
\text { bisdigitoxoside }\end{array}$ \\
\hline 51 & 118915216 & $\begin{array}{l}\text { Digoxigenin } \\
\text { bisdigitoxoside }\end{array}$ \\
\hline 52 & 4214612 & Valrubicin \\
\hline 53 & 95617679 & Telithromycin \\
\hline 54 & 95618786 & Zafirlukast \\
\hline 55 & 95617638 & Imatinib metabolite \\
\hline 56 & 11677901 & Bemotrizinol \\
\hline 57 & 49918330 & Valrubicin \\
\hline 58 & 95564895 & $\begin{array}{l}\text { Aripiprazole } \\
\text { Lauroxil }\end{array}$ \\
\hline 59 & 85537078 & Vinflunine \\
\hline 60 & 40164432 & Lutein \\
\hline 61 & 101160855 & Maraviroc \\
\hline 62 & 95618827 & Hydroxyitraconazole \\
\hline 63 & 169369935 & $\begin{array}{l}\text { 3'-p- } \\
\text { Hydroxypaclitaxel }\end{array}$ \\
\hline 64 & 11616852 & Valrubicin \\
\hline 65 & 85537091 & Proglumetacin \\
\hline 66 & 3831151 & Montelukast \\
\hline 67 & 68202099 & Sonidegib \\
\hline 68 & 36701290 & Ponatinib \\
\hline
\end{tabular}

\begin{tabular}{|c|c|c|}
\hline Rank & ZINC ID & Name \\
\hline 69 & 150338703 & Carbetocin \\
\hline 70 & 14879961 & Leutein \\
\hline 71 & 85537142 & Aclarubicin \\
\hline 72 & 11677890 & Bemotrizinol \\
\hline 73 & 685933138 & Rifapentine \\
\hline 74 & 3831511 & Ternadin \\
\hline 75 & 4097309 & Fosinopril \\
\hline 76 & 261527149 & Ivermectin \\
\hline 77 & 3995811 & Faslodex \\
\hline 78 & 601274 & Astemizole \\
\hline 79 & 95617639 & AFN911 \\
\hline 80 & 85540202 & Asunaprevir \\
\hline 81 & 96006024 & Spinosad \\
\hline 82 & 52955754 & Ergotamine \\
\hline 83 & 43131420 & Fostamatinib \\
\hline 84 & 3992480 & Telaprevir \\
\hline 85 & 85555528 & Vinblastine \\
\hline 86 & 4097185 & Reserpinin \\
\hline 87 & 21981272 & Hydroxynefazodone \\
\hline 88 & 94303244 & Desacetylvinblastine \\
\hline 89 & 85537014 & Cobicistat \\
\hline 90 & 85536958 & Vinorelbine \\
\hline 91 & 205224698 & Fosnetupitant \\
\hline 92 & 204073689 & Vorapaxar \\
\hline 93 & 3817234 & Maraviroc \\
\hline 94 & 100003902 & Maraviroc \\
\hline 95 & 148723177 & Brigatinib \\
\hline 96 & 53683271 & Dalfopristin \\
\hline 97 & 3995616 & Ergoloid \\
\hline 98 & 28232746 & Valrubicin \\
\hline 99 & 28232755 & Valrubicin \\
\hline 100 & 261139420 & Alcuronium \\
\hline
\end{tabular}


Table 2. Top 100 hits from a database of approved drugs, as identified by rank-by-number consensus scoring scheme utilizing five different scoring functions.

\begin{tabular}{|c|c|c|}
\hline Rank & ZINC ID & Name \\
\hline 1 & 26664090 & Saquinavir \\
\hline 2 & 11677911 & Bisoctrizole \\
\hline 3 & 3914596 & Saquinavir \\
\hline 4 & 85537091 & Proglumetacin \\
\hline 5 & 150588351 & Elbasvir \\
\hline 6 & 150601177 & Ombitasvir \\
\hline 7 & 26985532 & Saquinavir \\
\hline 8 & 169368439 & Saralasin \\
\hline 9 & 29416466 & Saquinavir \\
\hline 10 & 261527202 & Rifapentine \\
\hline 11 & 11677894 & Bemotrizinol \\
\hline 12 & 238809663 & Atracurium besylate \\
\hline 13 & 685933138 & Rifapentine \\
\hline 14 & 3941496 & Atazanavir \\
\hline 15 & 85537089 & Proglumetacin \\
\hline 16 & 261106255 & Senktide \\
\hline 17 & 49841054 & Carfilzomib \\
\hline 18 & 150339320 & Hydroxyitraconazole \\
\hline 19 & 8214644 & Pentagastrin \\
\hline 20 & 245224178 & Crocin \\
\hline 21 & 11677890 & Bemotrizinol \\
\hline 22 & 169289386 & Saralasin \\
\hline 23 & 150339052 & Nabumetone \\
\hline 24 & 85537142 & Aclarubicin \\
\hline 25 & 238809662 & Atracurium besylate \\
\hline 26 & 261494702 & Tricrocin \\
\hline 27 & 96006014 & Atracurium besylate \\
\hline 28 & 252441679 & Tylosin tartrate \\
\hline 29 & 150340074 & Sorbitan trioleate \\
\hline 30 & 261494569 & $\begin{array}{l}\text { 3-ene-Valproic acid } \\
\text { CoA }\end{array}$ \\
\hline 31 & 229984054 & $\begin{array}{l}\text { 4-ene-Valproic acid } \\
\text { CoA }\end{array}$ \\
\hline 32 & 150338703 & Carbetocin \\
\hline 33 & 11677901 & Bemotrizinol \\
\hline 34 & 261106254 & Senktide \\
\hline
\end{tabular}

\begin{tabular}{|c|c|c|}
\hline Rank & ZINC ID & Name \\
\hline 35 & 230123065 & Valproic Acid CoA \\
\hline 36 & 27990463 & Lomitapide \\
\hline 37 & 8215434 & $\begin{array}{l}\text { Flavin adenine } \\
\text { dinucleotide }\end{array}$ \\
\hline 38 & 238809665 & Atracurium besylate \\
\hline 39 & 72190231 & Posaconazole \\
\hline 40 & 95617677 & Pentagastrin \\
\hline 41 & 238809664 & Atracurium besylate \\
\hline 42 & 261494704 & Tricrocin \\
\hline 43 & 96006013 & Cisatracurium \\
\hline 44 & 118915215 & $\begin{array}{l}\text { Digoxigenin } \\
\text { bisdigitoxoside }\end{array}$ \\
\hline 45 & 118915214 & $\begin{array}{l}\text { Digoxigenin } \\
\text { bisdigitoxoside }\end{array}$ \\
\hline 46 & 118915216 & $\begin{array}{l}\text { Digoxigenin } \\
\text { bisdigitoxoside }\end{array}$ \\
\hline 47 & 8214658 & Pipotiazine \\
\hline 48 & 169621228 & Rifapentine \\
\hline 49 & 169621210 & Voacamine \\
\hline 50 & 96006015 & Atracurium besylate \\
\hline 51 & 96006020 & Paclitaxel \\
\hline 52 & 8552309 & $\begin{array}{l}\text { Palmitoyloleoyl- } \\
\text { phosphatidylglycerol }\end{array}$ \\
\hline 53 & 95564895 & Aripiprazole \\
\hline 54 & 3831151 & Montelukast \\
\hline 55 & 100022637 & Tipranavir \\
\hline 56 & 100016058 & Tipranavir \\
\hline 57 & 95618745 & RPR123142 \\
\hline 58 & 95618746 & RPR123142 \\
\hline 59 & 1530755 & Probucol \\
\hline 60 & 261106252 & Senktide \\
\hline 61 & 6845076 & B-Carotene \\
\hline 62 & 261494703 & Tricrocin \\
\hline 63 & 8214373 & Colfosceril palmitate \\
\hline 64 & 169677008 & Everolimus \\
\hline 65 & 8220175 & Zeaxanthin \\
\hline 66 & 85537014 & Cobicistat \\
\hline 67 & 3938642 & Thymopentin \\
\hline 68 & 49918329 & Valrubicin \\
\hline
\end{tabular}

\begin{tabular}{|c|c|c|}
\hline Rank & ZINC ID & Name \\
\hline 69 & 261527149 & Ivermectin \\
\hline 70 & 95617679 & Telithromycin \\
\hline 71 & 85537068 & Pralmorelin \\
\hline 72 & 164528615 & Glecaprevir \\
\hline 73 & 4097427 & Candesartan \\
\hline 74 & 3995811 & Faslodex \\
\hline 75 & 85555528 & Vinblastine \\
\hline 76 & 22448696 & Indinavir \\
\hline 77 & 95615286 & Senktide \\
\hline 78 & 253630390 & Ivermectin \\
\hline 79 & 261494615 & Fidaxomicin \\
\hline 80 & 85574641 & Ubiquinol \\
\hline 81 & 3992480 & Telaprevir \\
\hline 82 & 28639340 & Posaconazole \\
\hline 83 & 164760756 & Simeprevir \\
\hline 84 & 72131401 & Hydroxyitraconazole \\
\hline 85 & 96006024 & Spinosad \\
\hline 86 & 3938482 & Posaconazole \\
\hline 87 & 936069565 & Glecaprevir \\
\hline 88 & 85427689 & Ubidecarenone \\
\hline 89 & 252286706 & Ivermectin \\
\hline 90 & 4097309 & Fosinopril \\
\hline 91 & 253632968 & Simeprevir \\
\hline 92 & 85536932 & Cabazitaxel \\
\hline 93 & 95618786 & Zafirlukast \\
\hline 94 & 96061888 & Roxithromycin \\
\hline 95 & 17653971 & Canthaxanthin \\
\hline 96 & 40164432 & Lutein \\
\hline 97 & 253975480 & Rifaximin \\
\hline 98 & 169369935 & $\begin{array}{l}3 \text { '-p- } \\
\text { Hydroxypaclitaxel }\end{array}$ \\
\hline 99 & 95551509 & Grazoprevir \\
\hline 100 & 253387884 & Hydroxyitraconazole \\
\hline
\end{tabular}


Table 3. The combined consensus hit list of total 91 unique approved drugs, predicted to target SARS-CoV-2 spike protein-ACE2 receptor interaction.

\begin{tabular}{|c|c|c|c|}
\hline No. & Drug Name & ZINC IDs & Drug Class/Target \\
\hline 1 & Asunaprevir & 85540202 & \multirow{14}{*}{ Antivirals } \\
\hline 2 & Atazanavir & 3941496 & \\
\hline 3 & Cobicistat & 85537014 & \\
\hline 4 & Daclatasvir & 68204830 & \\
\hline 5 & Elbasvir & 150588351 & \\
\hline 6 & Glecaprevir & 164528615,936069565 & \\
\hline 7 & Grazoprevir & 95551509 & \\
\hline 8 & Indinavir & 22448696 & \\
\hline 9 & Ombitasvir & 150601177 & \\
\hline 10 & Saquinavir & $\begin{array}{l}3914596,26664090, \\
29416466,26985532\end{array}$ & \\
\hline 11 & Simeprevir & 253632968,164760756 & \\
\hline 12 & Telaprevir & 3992480 & \\
\hline 13 & Tipranavir & 100022637,100016058 & \\
\hline 14 & Voxilaprevir & 218037687 & \\
\hline 15 & B-Carotene & 6845076 & \multirow{9}{*}{ Antioxidants } \\
\hline 16 & Canthaxanthin & 17653971 & \\
\hline 17 & Crocin & 245224178 & \\
\hline 18 & Flavin adenine dinucleotide & 8215434 & \\
\hline 19 & Lutein & 14879961, 40164432 & \\
\hline 20 & Tricrocin & $\begin{array}{l}261494702,261494704, \\
261494703\end{array}$ & \\
\hline 21 & Ubidecarenone & 85427689 & \\
\hline 22 & Ubiquinol & 85574641 & \\
\hline 23 & Zeaxanthin & 8220175 & \\
\hline 24 & Nabumetone & 150339052 & \multirow{3}{*}{ Anti-inflammatory } \\
\hline 25 & Proglumetacin & 85537091,85537089 & \\
\hline 26 & Fostamatinib & 43131420 & \\
\hline 27 & Aclarubicin & 85537142 & \multirow{6}{*}{ Antibiotics } \\
\hline 28 & Dalfopristin & 53683271 & \\
\hline 29 & Fidaxomicin & 261494615 & \\
\hline 30 & Rifapentine & $\begin{array}{l}685933138,261527202, \\
169621228\end{array}$ & \\
\hline 31 & Rifaximin & 253975480 & \\
\hline 32 & Roxithromycin & 96061888 & \\
\hline
\end{tabular}




\begin{tabular}{|c|c|c|c|}
\hline 33 & Telithromycin & 95617679 & \multirow[b]{3}{*}{ Antibiotics } \\
\hline 34 & Tylosin tartrate & 252441679 & \\
\hline 35 & Valrubicin & $\begin{array}{l}\text { 49918329, 49783788, } \\
4214612,49918330, \\
11616852,28232746, \\
28232755\end{array}$ & \\
\hline 36 & Hydroxyitraconazole & $\begin{array}{l}253387884,150339320, \\
150339325,150339328, \\
72131401,95618827\end{array}$ & \multirow{3}{*}{ Antifungals } \\
\hline 37 & Itraconazole & 4097344 & \\
\hline 38 & Posaconazole & $\begin{array}{l}72190231,60392779 \\
28639340,3938482\end{array}$ & \\
\hline 39 & 3'-p-Hydroxypaclitaxel & 169369935 & \multirow{14}{*}{ Anticancer drugs } \\
\hline 40 & AFN911 & $\begin{array}{l}\text { 95617640, } 95617638, \\
95617639\end{array}$ & \\
\hline 41 & Brigatinib & 148723177 & \\
\hline 42 & Cabazitaxel & 85536932 & \\
\hline 43 & Carfilzomib & 49841054 & \\
\hline 44 & Desacetylvinblastine & 94303244 & \\
\hline 45 & Faslodex & 3995811 & \\
\hline 46 & Paclitaxel & 96006020 & \\
\hline 47 & Ponatinib & 36701290 & \\
\hline 48 & RPR123142 & 95618745,95618746 & \\
\hline 49 & Sonidegib & 68202099 & \\
\hline 50 & Vinblastine & 85555528 & \\
\hline 51 & Vinflunine & 85537078 & \\
\hline 52 & Vinorelbine & 85536958 & \\
\hline 53 & Fosinopril & 4097309 & \multirow{4}{*}{$\begin{array}{l}\text { Antihypertensives (ACE Inhibitors and } \\
\text { angiotensin-receptor blockers) }\end{array}$} \\
\hline 54 & Reserpinin & 4097185 & \\
\hline 55 & Candesartan & 4097427,4074875 & \\
\hline 56 & Saralasin & 169368439,169289386 & \\
\hline 57 & Ivermectin & $\begin{array}{l}261527149,253630390 \\
252286706\end{array}$ & \multirow{3}{*}{ Antiparasitic drugs } \\
\hline 58 & Spinosad & 96006024 & \\
\hline 59 & Voacamine & 169621210,169621209 & \\
\hline 60 & Alcuronium & 261139420 & \multirow{3}{*}{ Neuromuscular blocking agents } \\
\hline 61 & Atracurium besylate & $\begin{array}{l}238809663,238809662 \\
96006014,238809665 \\
238809664,96006015\end{array}$ & \\
\hline 62 & Cisatracurium & 96006013 & \\
\hline
\end{tabular}




\begin{tabular}{|c|c|c|c|}
\hline 63 & 3-ene-Valproic acid CoA & 261494569 & \multirow{3}{*}{ Anticonvulsants } \\
\hline 64 & 4-ene-Valproic acid CoA & 229984054 & \\
\hline 65 & Valproic Acid CoA & 230123065 & \\
\hline 66 & Montelukast & 3831151 & \multirow{2}{*}{ Leukotriene receptor antagonists } \\
\hline 67 & Zafirlukast & 896717,95618786 & \\
\hline 68 & Palmitoyloleoyl-phosphatidylglycerol & 8552309 & \multirow{2}{*}{ Pulmonary surfactants } \\
\hline 69 & Colfosceril palmitate & 8214373 & \\
\hline 70 & Astemizole & 601274 & \multirow{2}{*}{ Antihistamines } \\
\hline 71 & Ternadin & 3831511 & \\
\hline 72 & Aripiprazole Lauroxil & 95564895 & \multirow{2}{*}{ Antipsychotics } \\
\hline 73 & Pipotiazine & 8214658 & \\
\hline 74 & Lomitapide & 27990463 & \multirow{2}{*}{ Hypolipidemic agents } \\
\hline 75 & Probucol & 1530755 & \\
\hline 76 & Bemotrizinol & $\begin{array}{l}\text { 11677894, 11677901, } \\
11677890\end{array}$ & \multirow[t]{2}{*}{ UV absorbers } \\
\hline 77 & Bisoctrizole & 11677911 & \\
\hline 78 & Carbetocin & 150338703 & Oxytocic \\
\hline 79 & Digoxigenin bisdigitoxoside & $\begin{array}{l}118915215,118915214, \\
118915216\end{array}$ & Cardiac glycoside \\
\hline 80 & Ergoloid & 3995616 & Vasodilator \\
\hline 81 & Ergotamine & 52955754 & Alpha-1 selective adrenergic agonist \\
\hline 82 & Everolimus & 169677008 & Immunosuppressant \\
\hline 83 & Fosnetupitant & 205224698 & Antiemetic \\
\hline 84 & Hydroxynefazodone & 21981272 & Antidepressant \\
\hline 85 & Maraviroc & $\begin{array}{l}\text { 101160855, 3817234, } \\
100003902\end{array}$ & Chemokine receptor antagonist \\
\hline 86 & Pentagastrin & 8214644,95617677 & Gastrin analogue \\
\hline 87 & Pralmorelin & 85537068 & Growth hormone-releasing peptide 2 \\
\hline 88 & Senktide & $\begin{array}{l}261106255,261106254 \\
261106252,95615286\end{array}$ & Neuromedin K3 (NK3) receptor agonist \\
\hline 89 & Temoporfin & 3934128 & Photosensitizer \\
\hline 90 & Thymopentin & 3938642 & Immunostimulant (against HIV) \\
\hline 91 & Vorapaxar & 204073689 & Inhibitor of protease-activated receptor \\
\hline
\end{tabular}


Figure 1. The SARS-CoV-2 spike protein-ACE2 receptor interface (PDB ID: 6M0J). The binding interfaces (shown in white rectangles) of isolated (A) ACE2 receptor and (B) spike protein receptor-binding domain lack any druggable pockets. (C) Together in their bound form, however, they present a well-defined, tunnel-like binding pocket (shown in white circle) with druggability score of 0.71 , making it suitable for binding a small-molecule modulator of therapeutic importance against Covid-19.
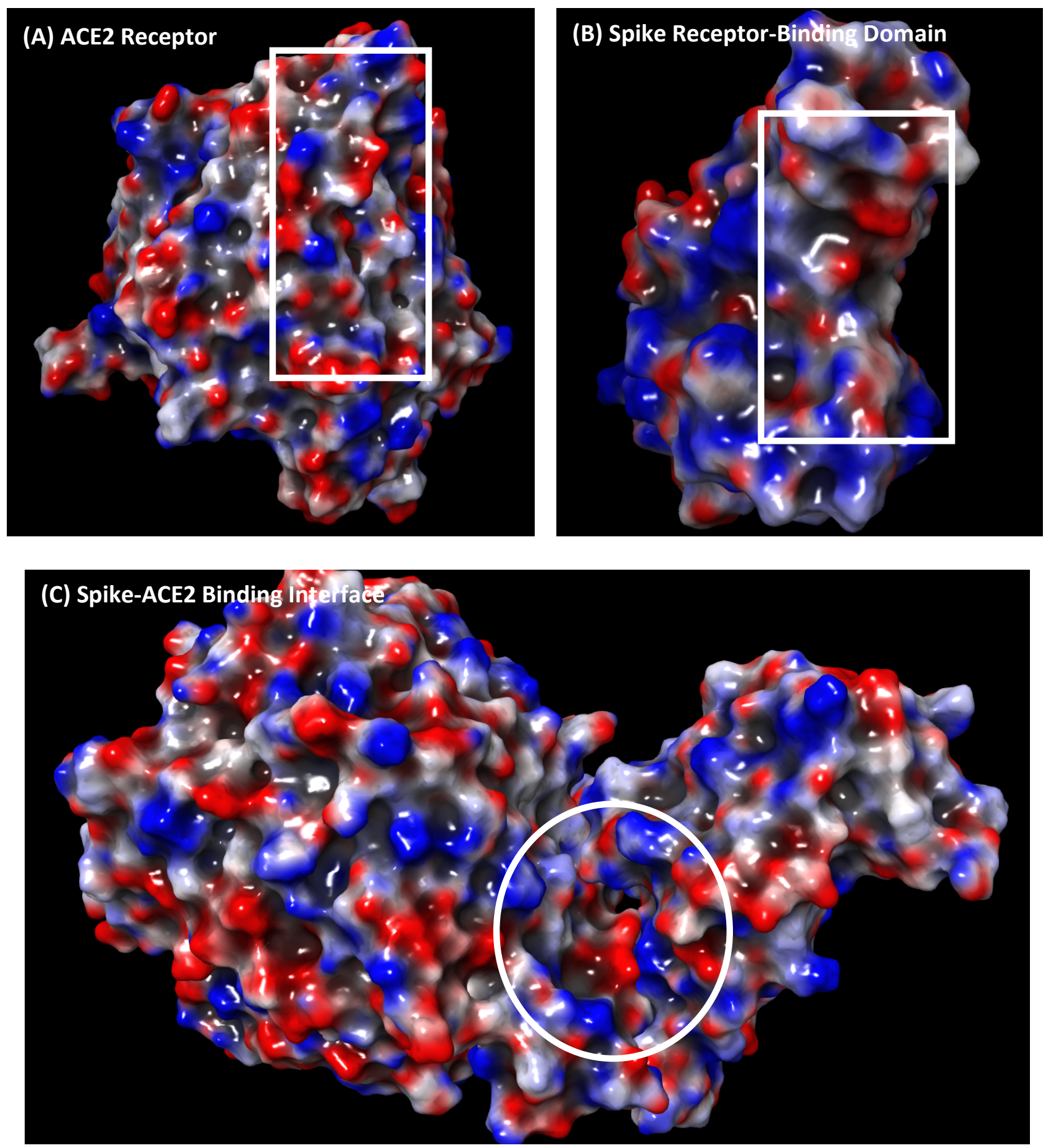
Figure 2. The predicted binding modes of top 10 representative hits at the SARS-CoV-2 spike protein-ACE2 receptor binding interface, and their associated 2D ligand-protein interaction diagrams: (1) Atazanavir, (2) Grazoprevir, (3) Saquinavir, (4) Simeprevir, (5) Telaprevir, (6) Tipranavir, (7) Aclarubicin, (8) Hydroxyitraconazole, (9) AFN911 (Imatinib metabolite), (10) Sonidegib, (11) Vinorelbine, (12) Fosinopril, (13) Candesartan, (14) Saralasin, (15) Voacamine, (16) Atracurium besylate, (17) Zafirlukast, (18) Astemizole, (19) Maraviroc, (20) Senktide.

\section{(1) Atazanavir:}
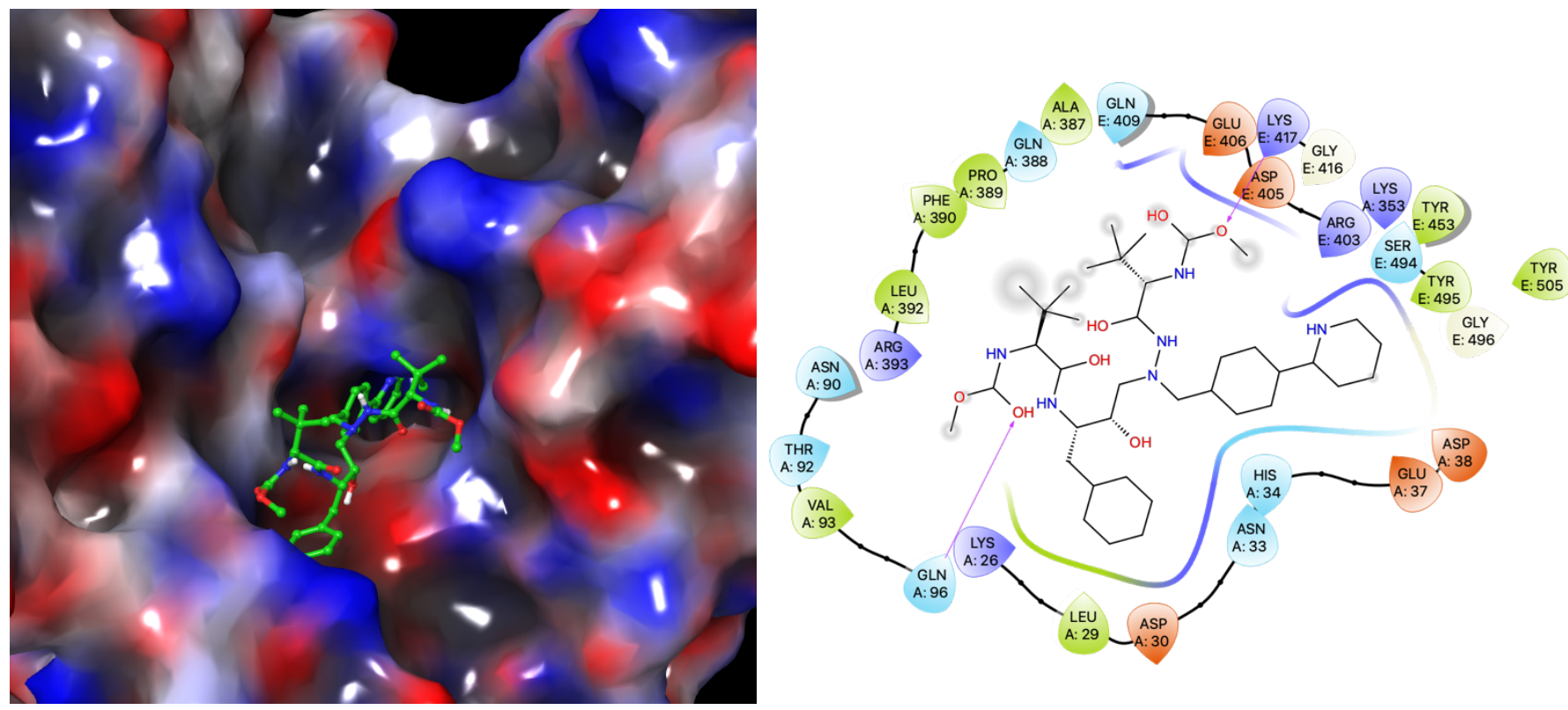

\section{(2) Grazoprevir:}
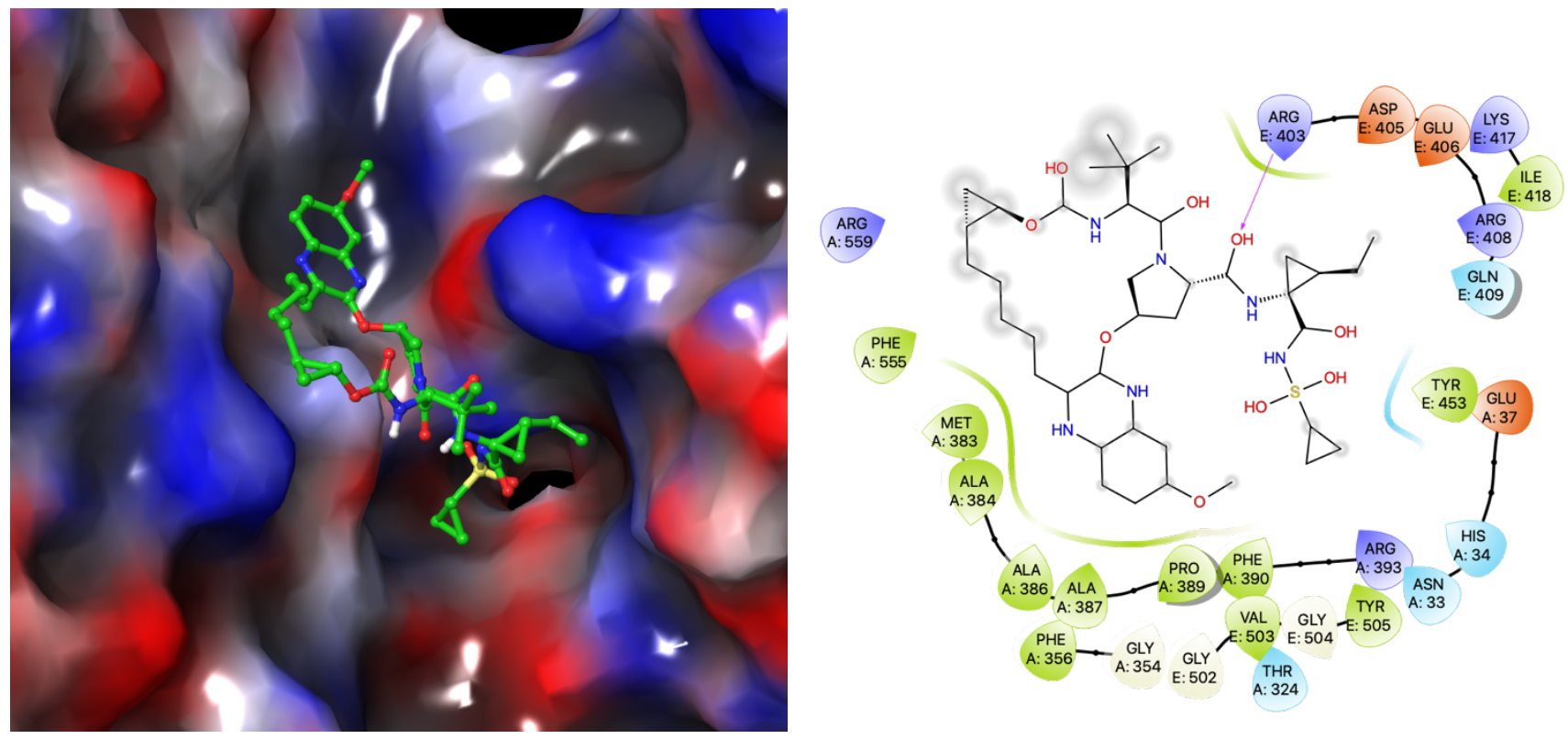
Figure 2 (continued)

\section{(3) Saquinavir:}
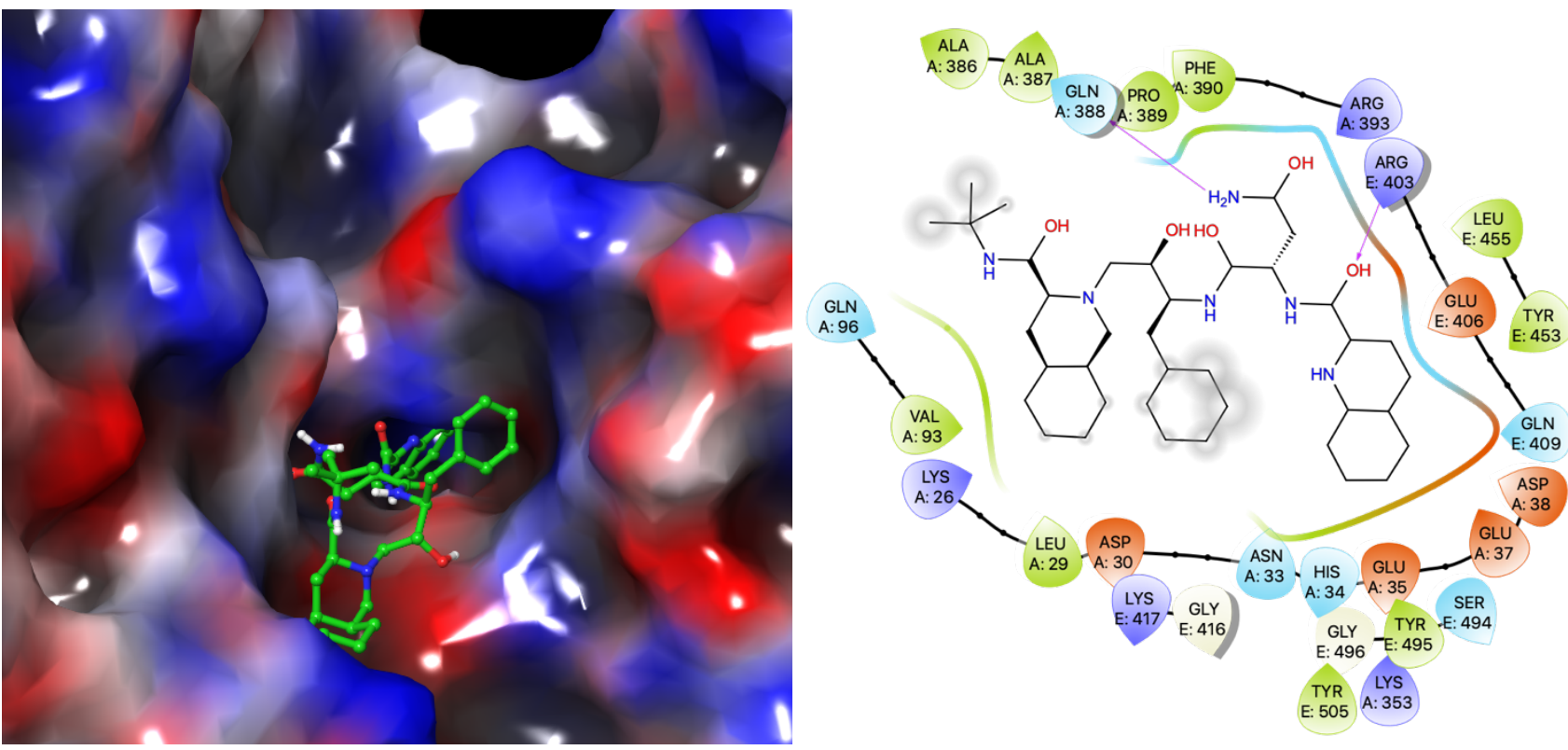

(4) Simeprevir:
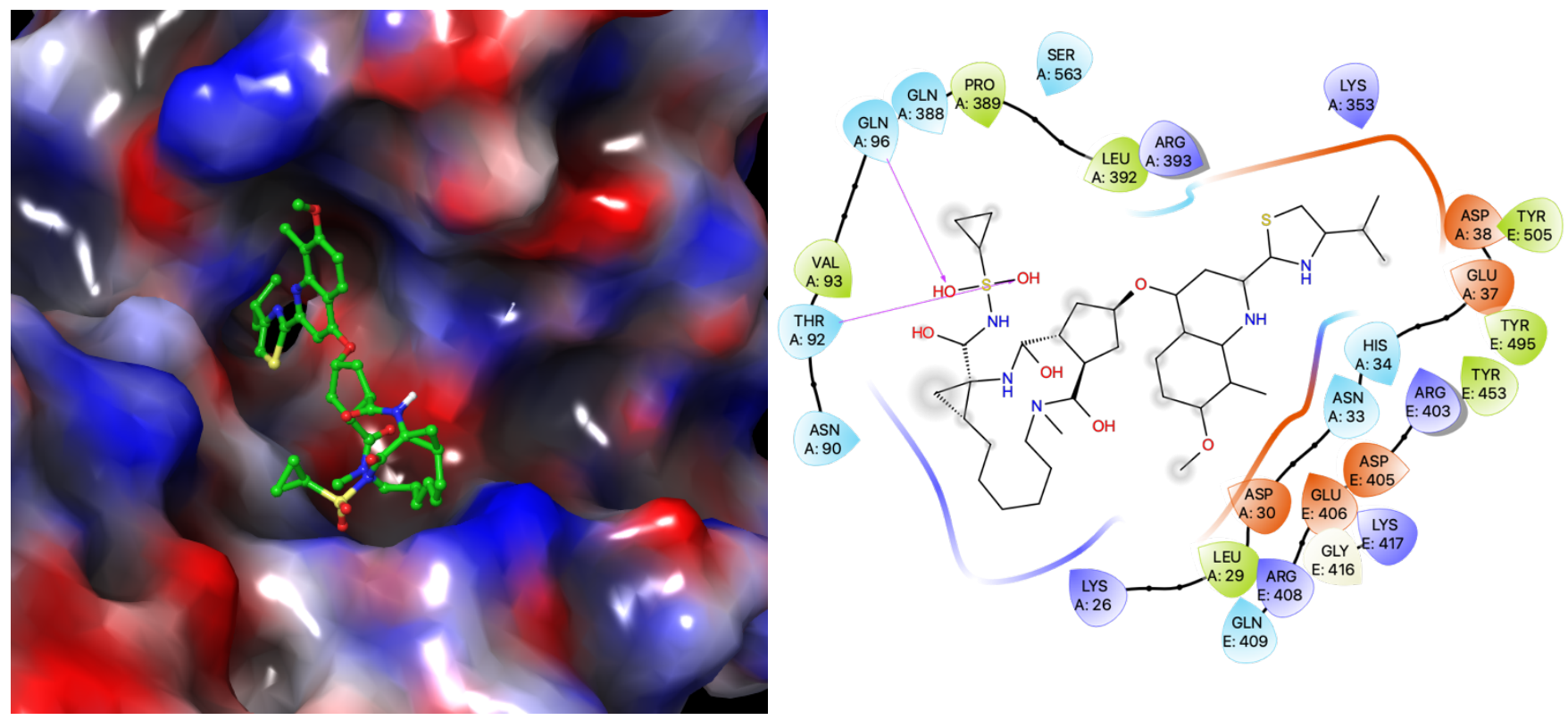
Figure 2 (continued)

\section{(5) Telaprevir:}
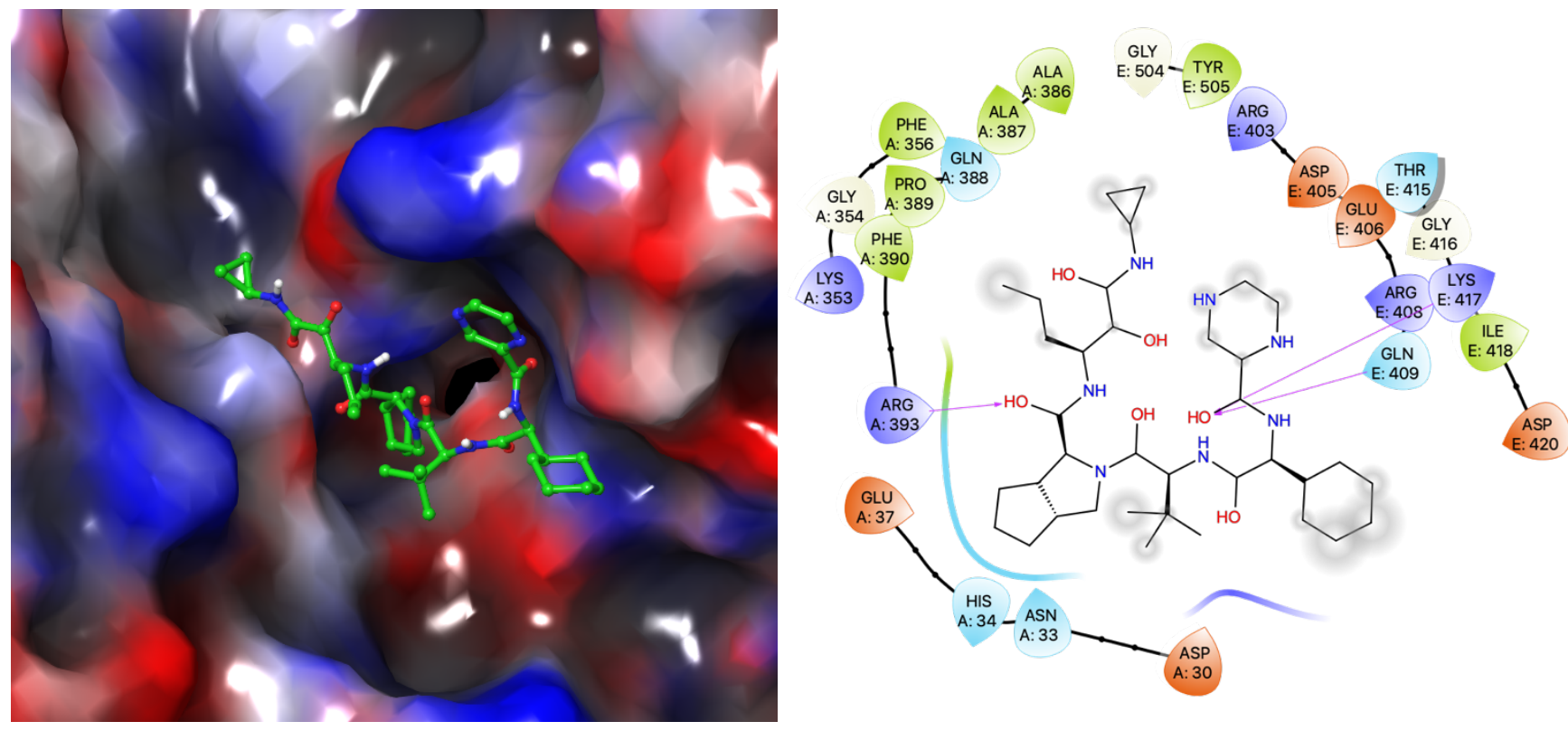

(6) Tipranavir:
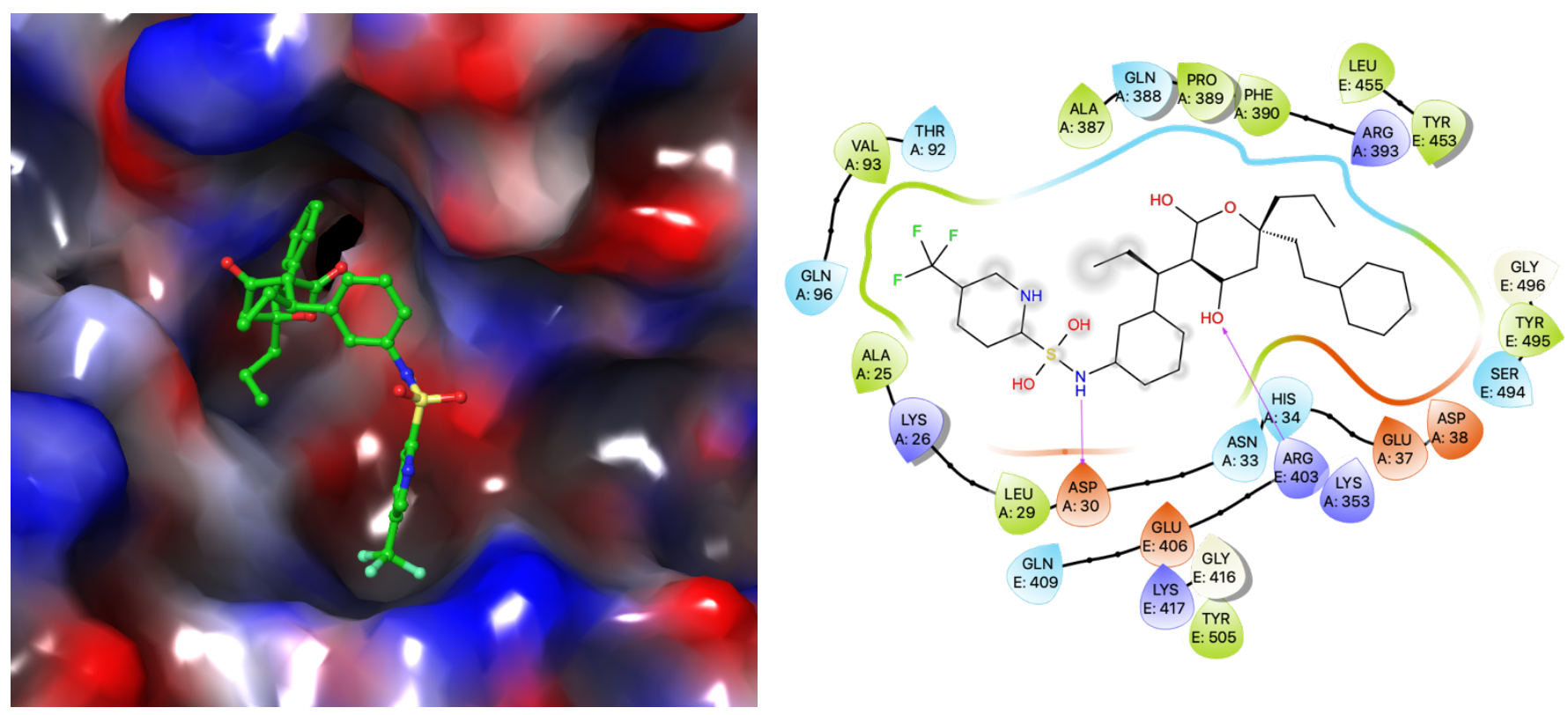
Figure 2 (continued)

\section{(7) Aclarubicin:}
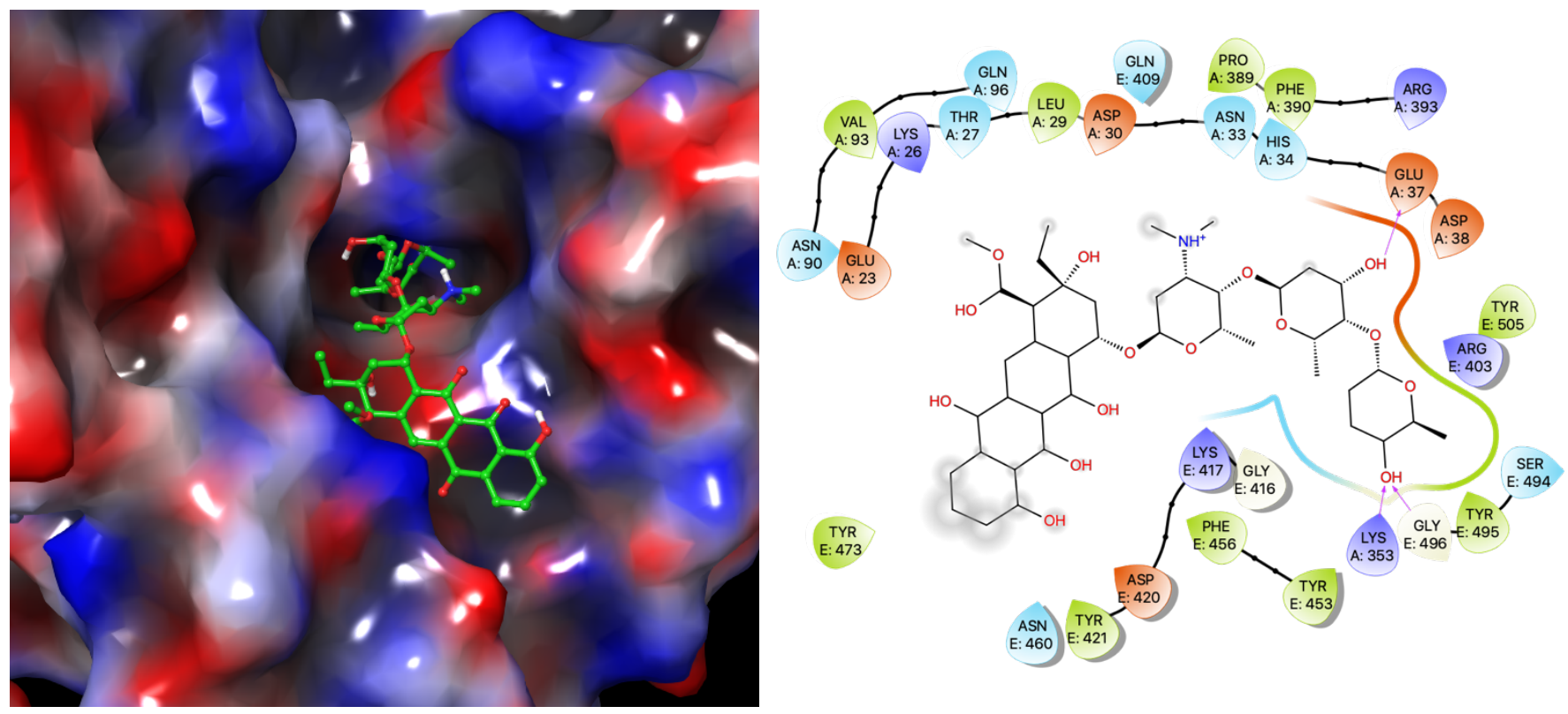

(8) Hydroxyitraconazole:
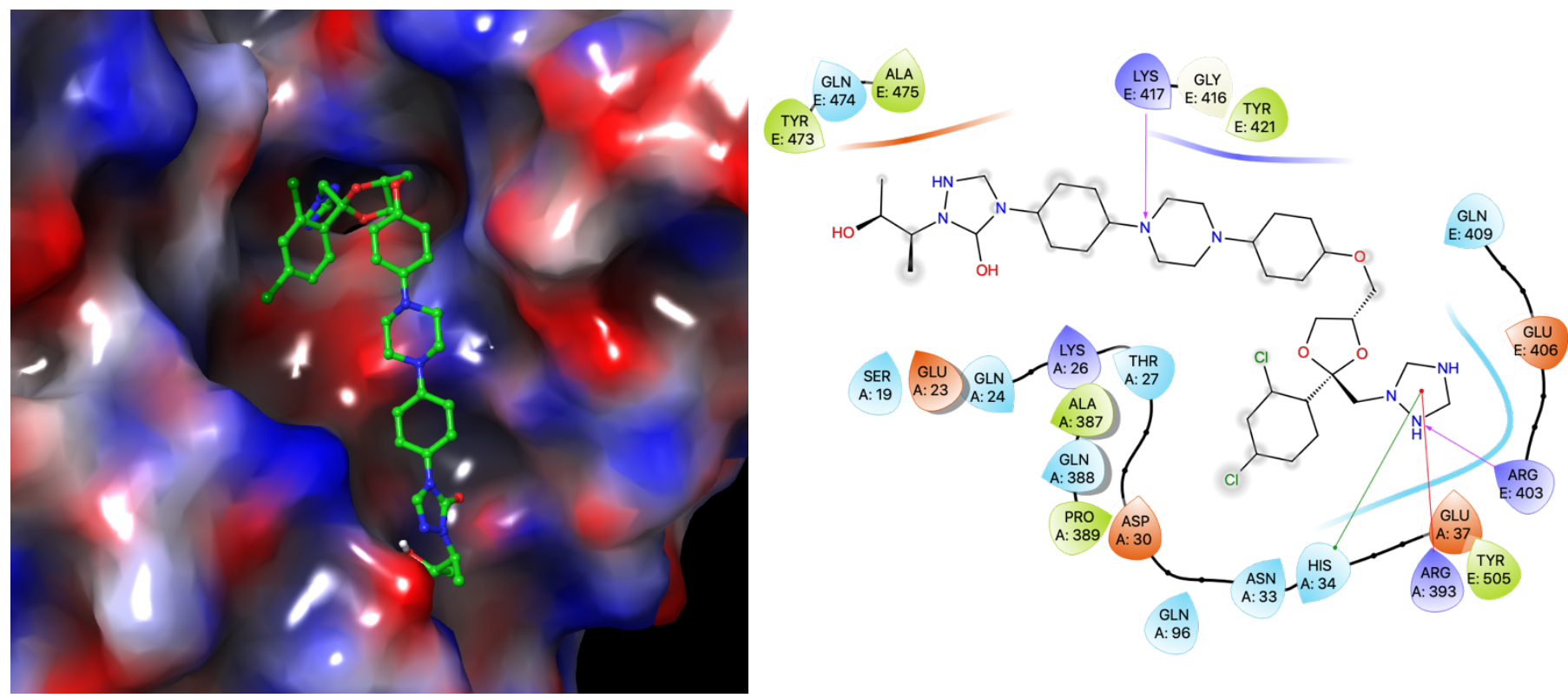
Figure 2 (continued)

(9) AFN911 (Imatinib metabolite):
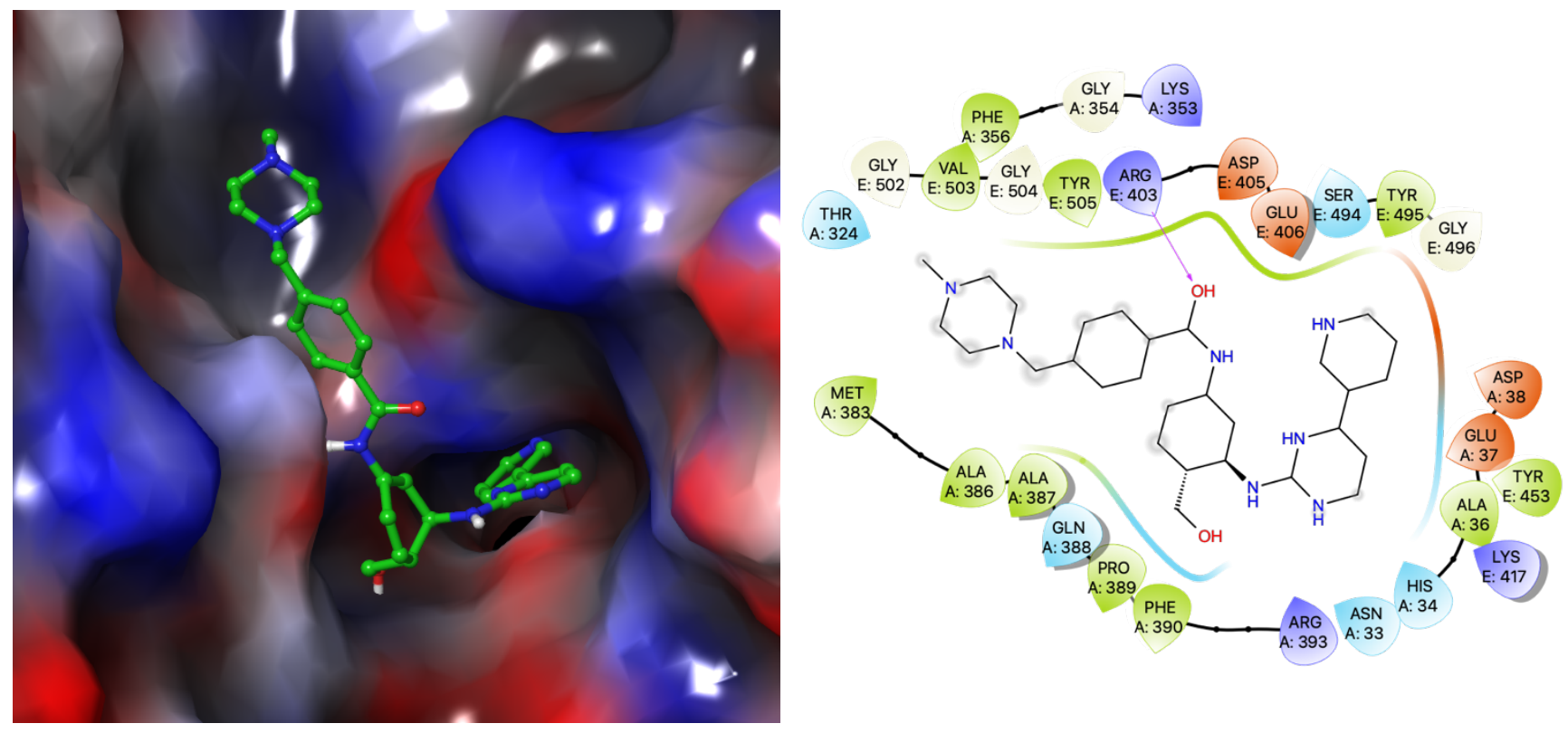

(10) Sonidegib:
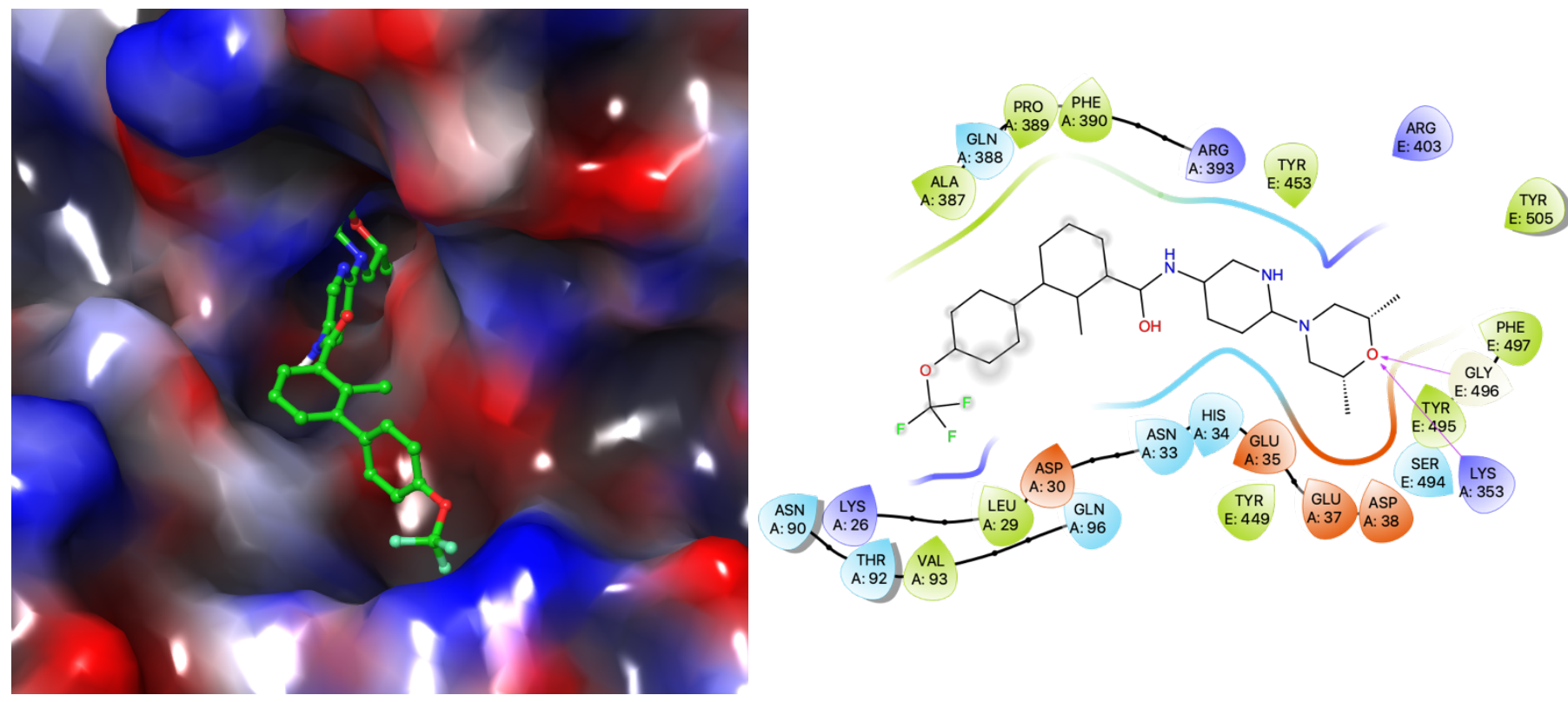
Figure 2 (continued)

\section{(11) Vinorelbine:}
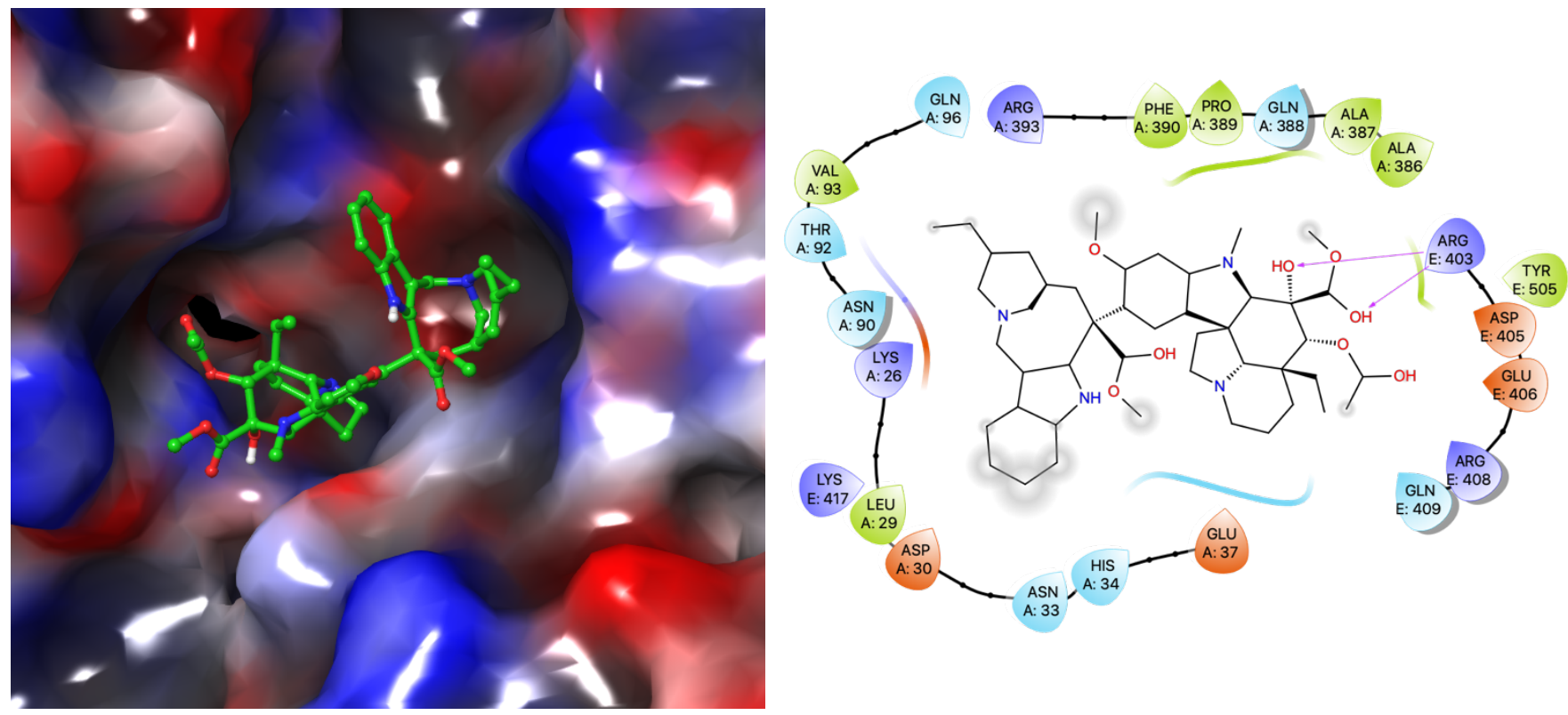

(12) Fosinopril:
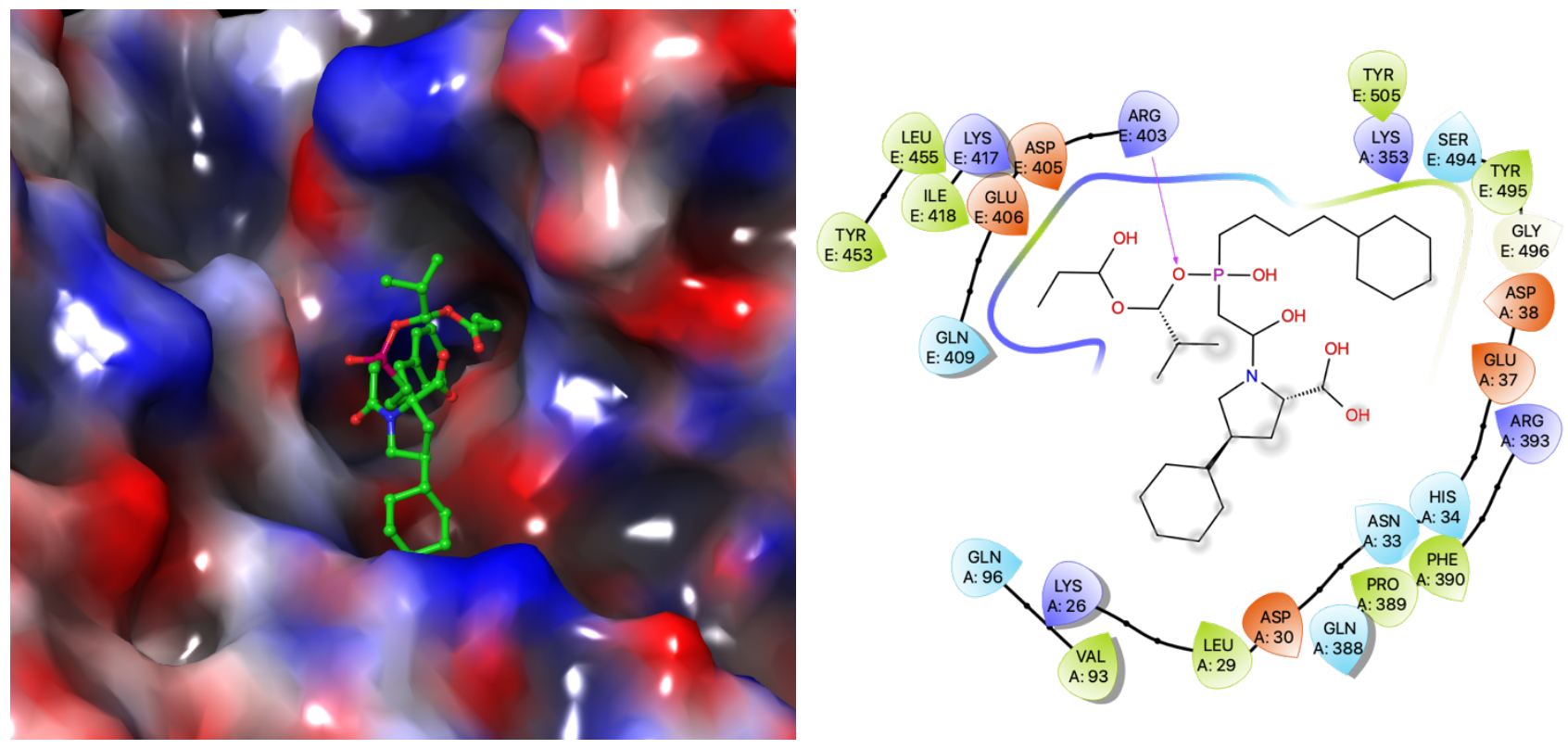
Figure 2 (continued)

\section{(13) Candesartan:}
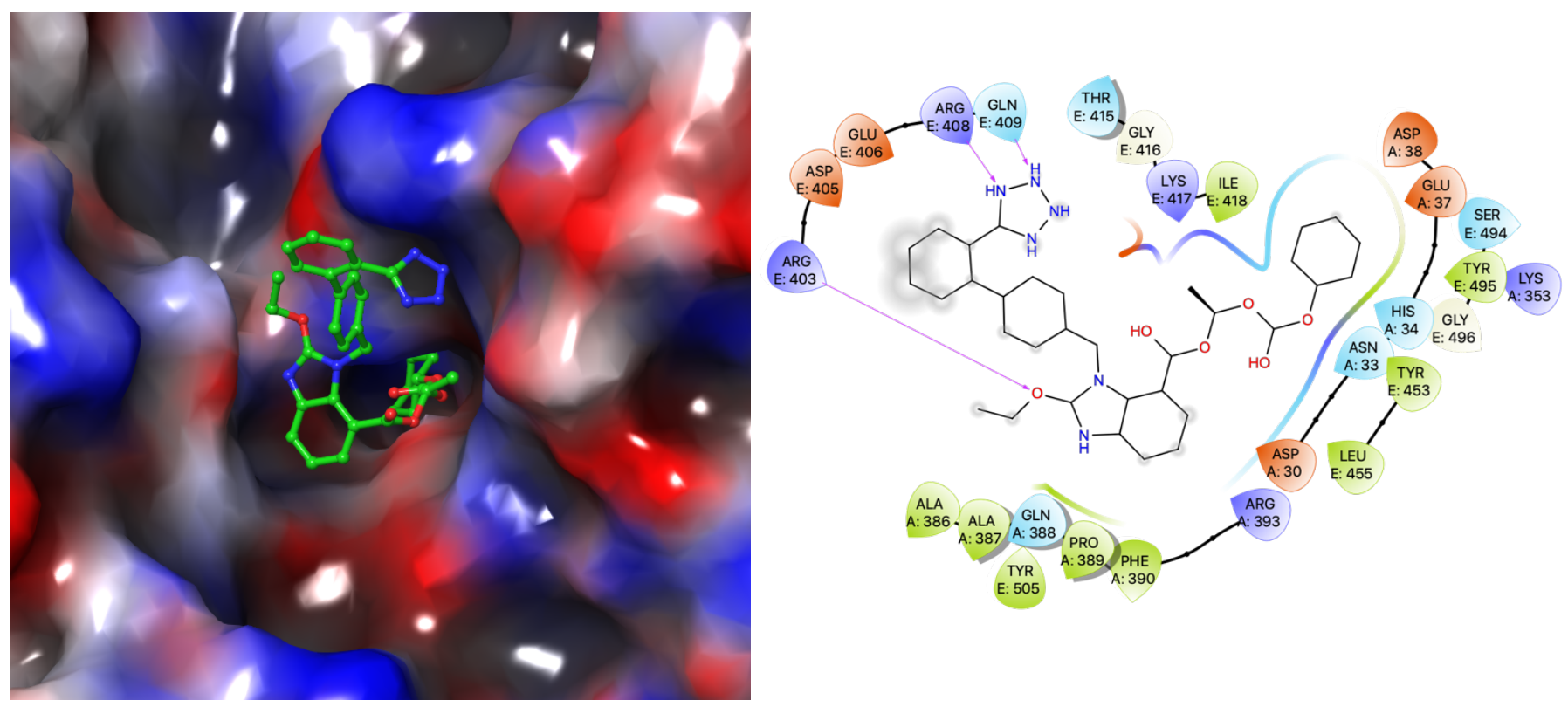

(14) Saralasin:
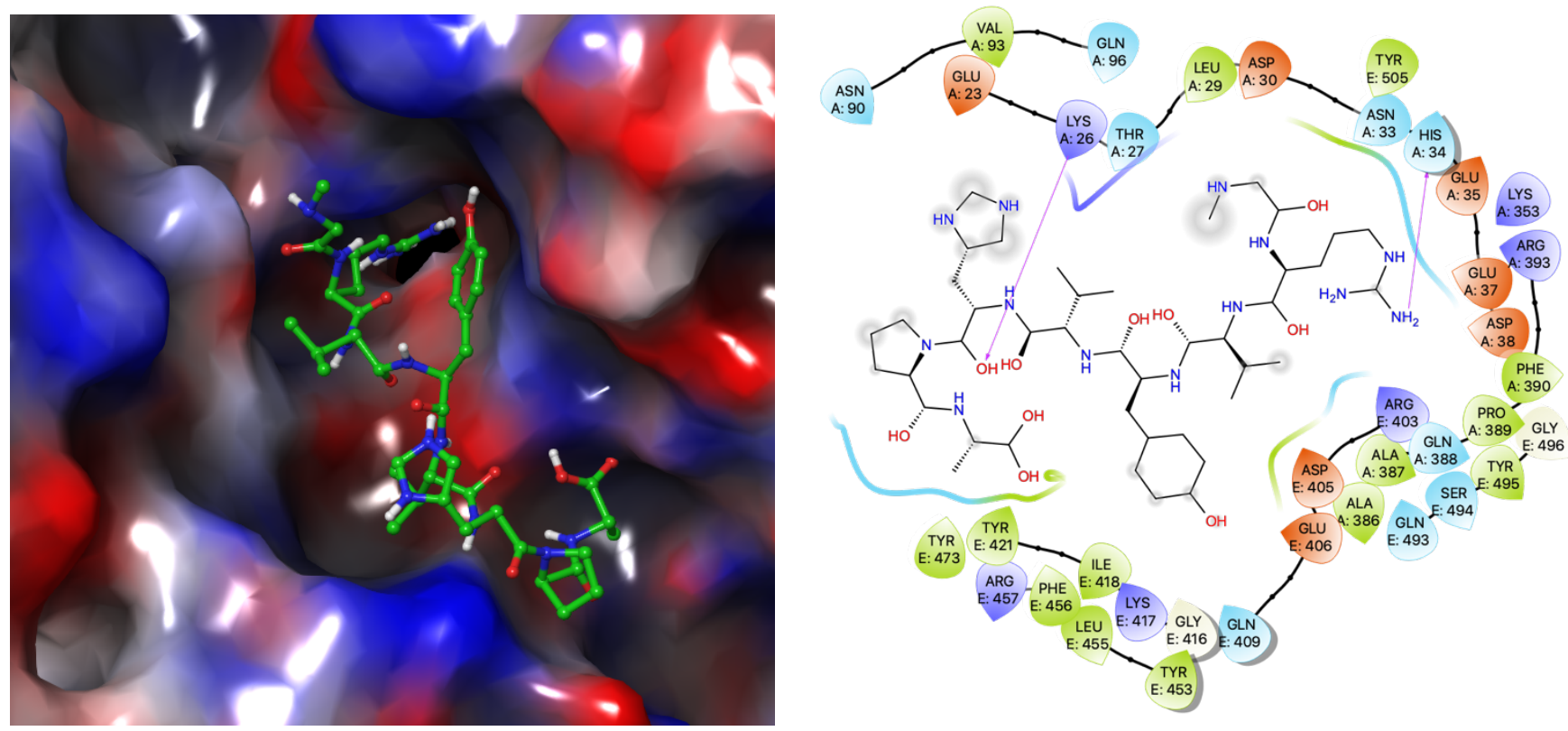
Figure 2 (continued)

\section{(15) Voacamine:}
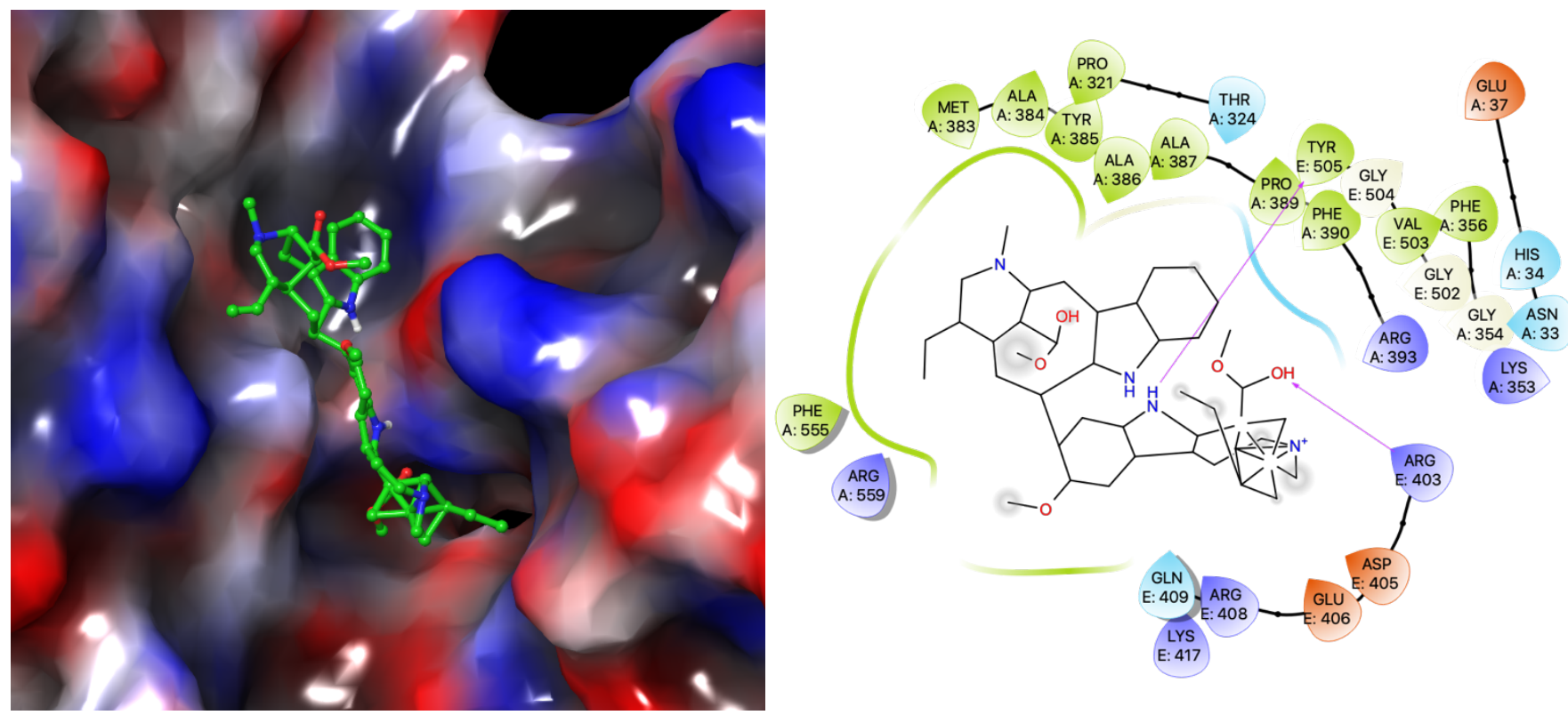

(16) Atracurium besylate:
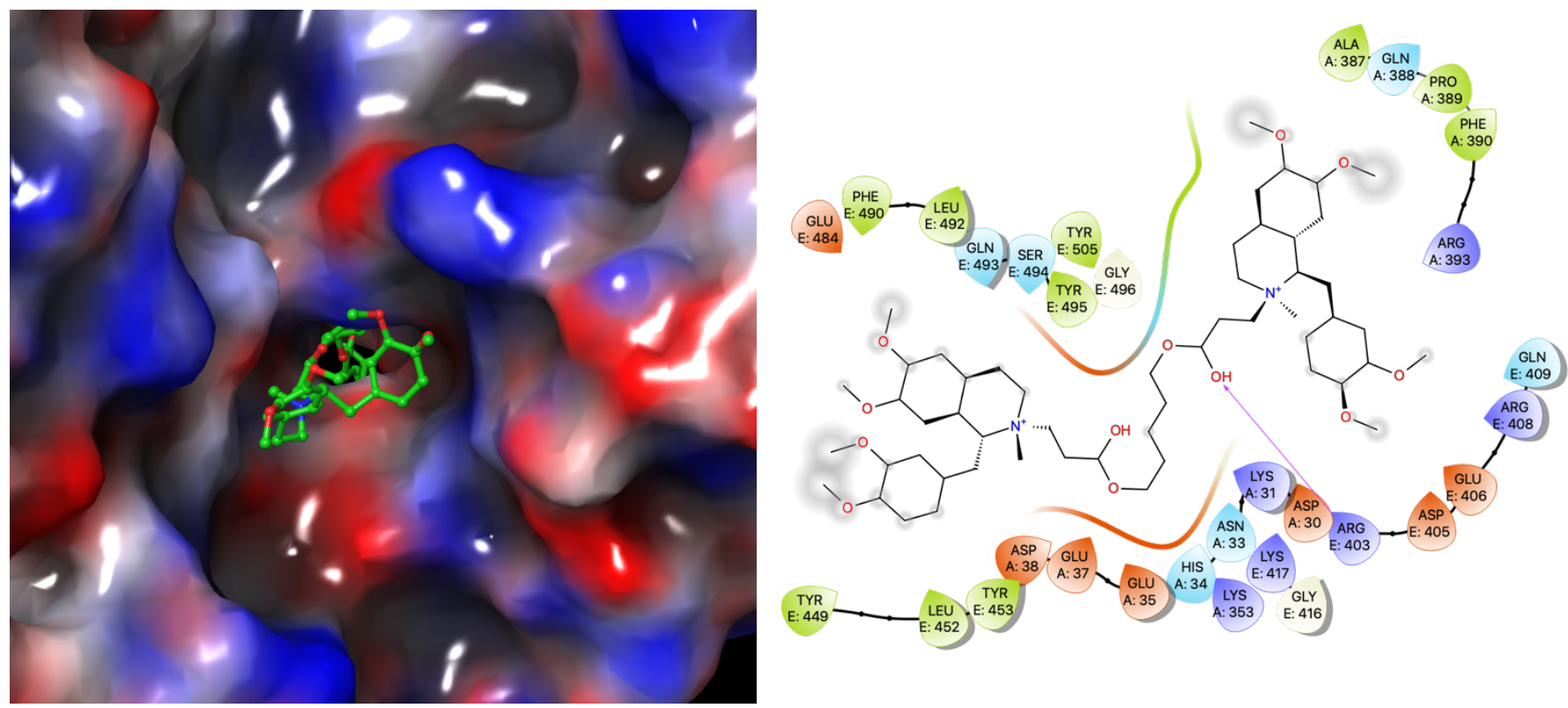
Figure 2 (continued)

\section{(17) Zafirlukast:}
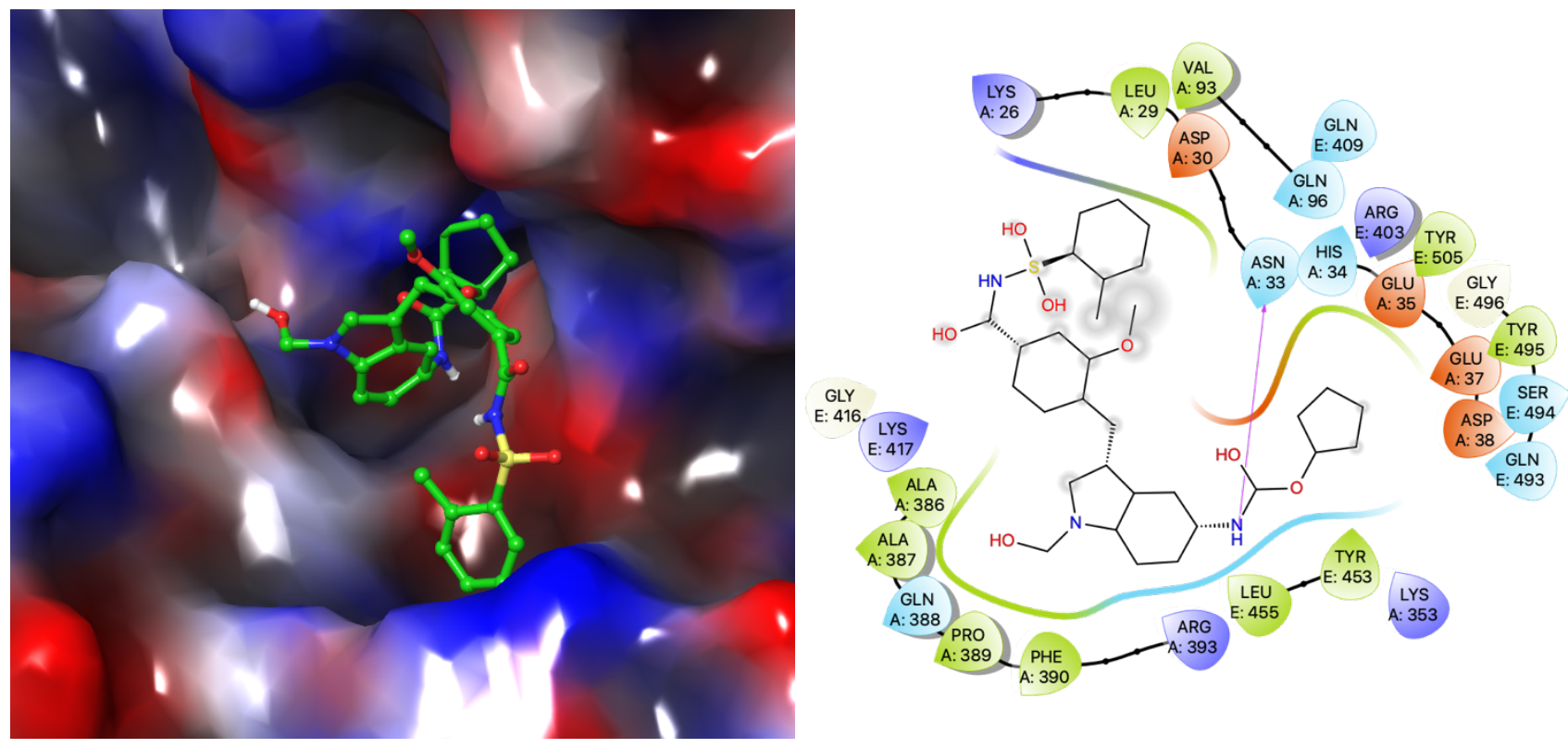

(18) Astemizole:
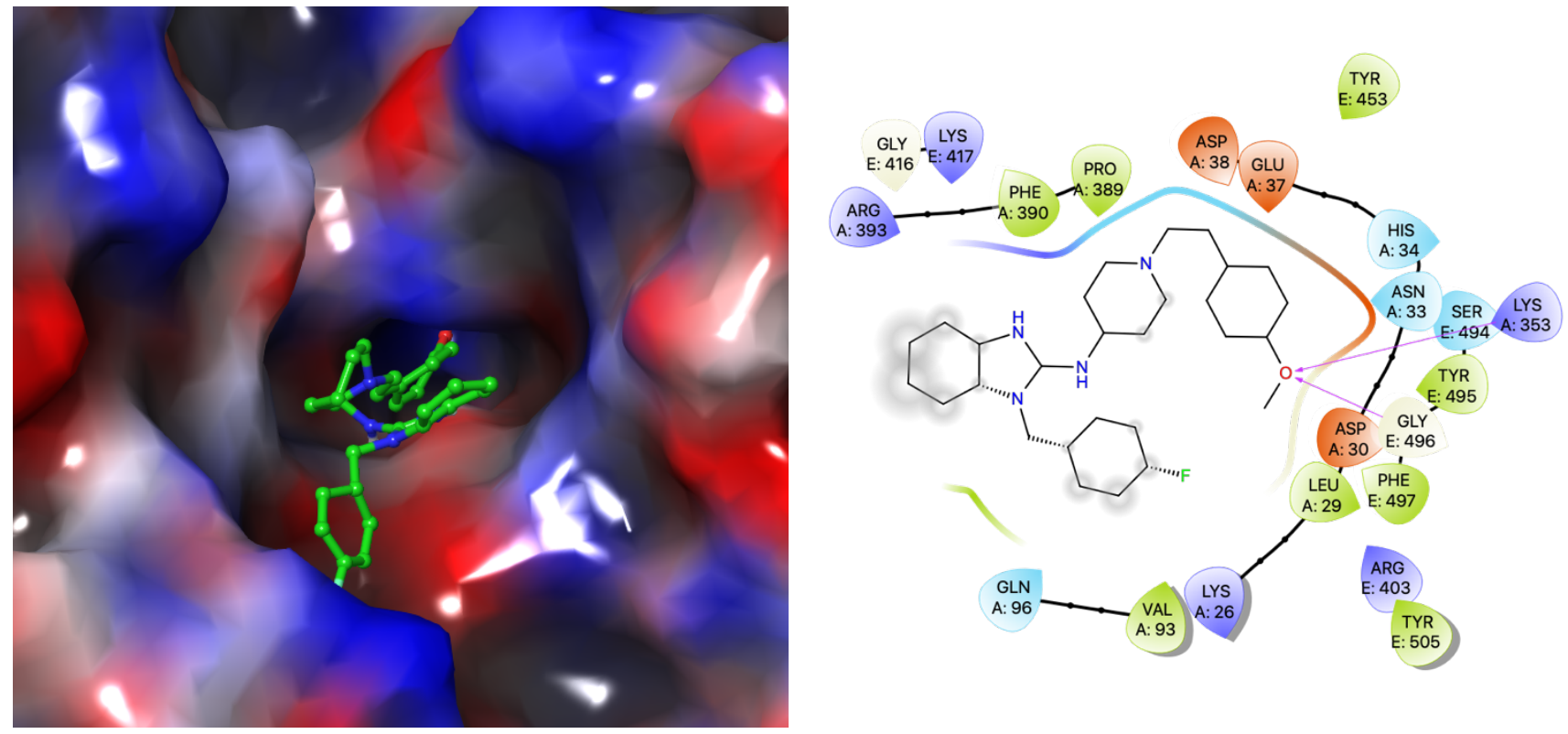
Figure 2 (continued)

\section{(19) Maraviroc:}
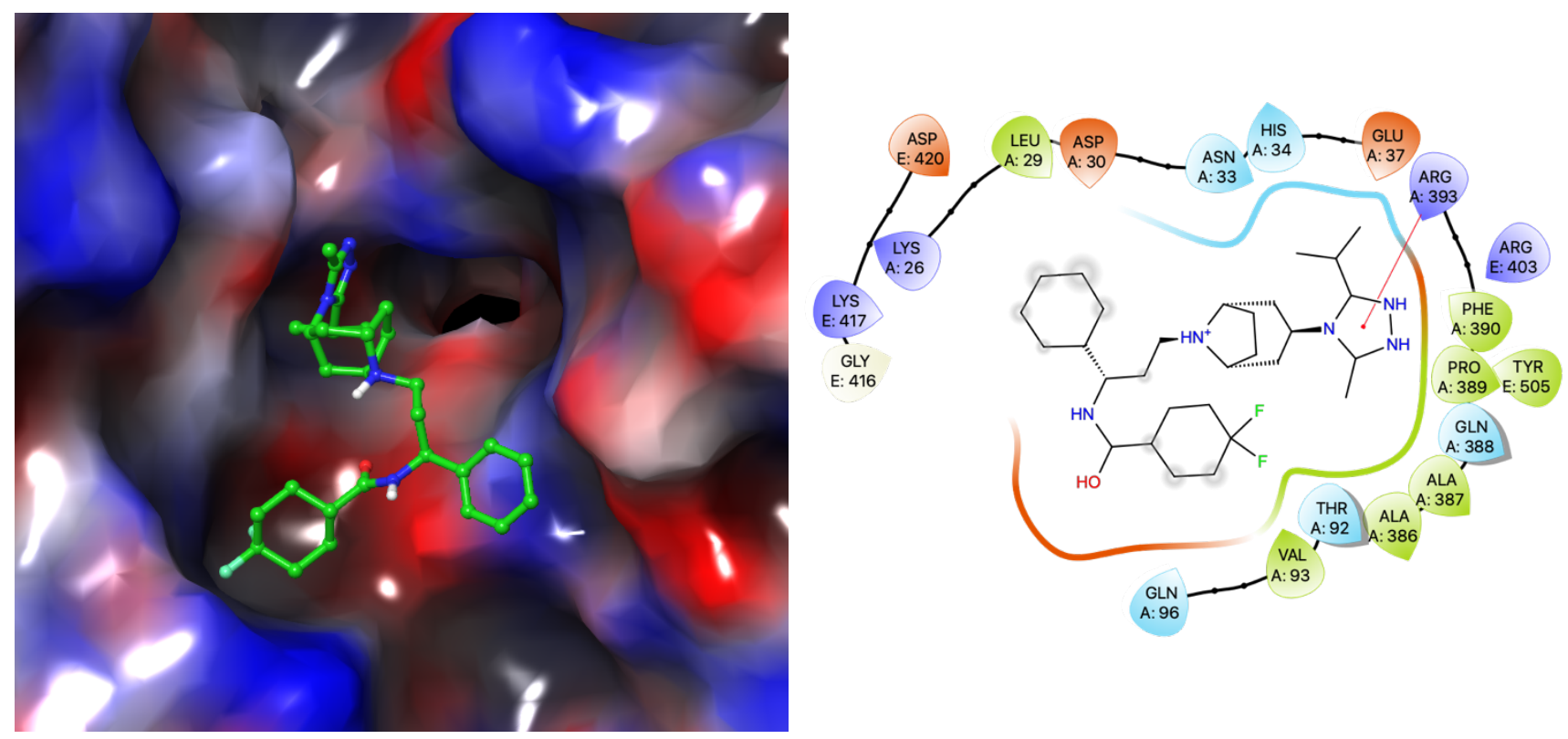

(20) Senktide:
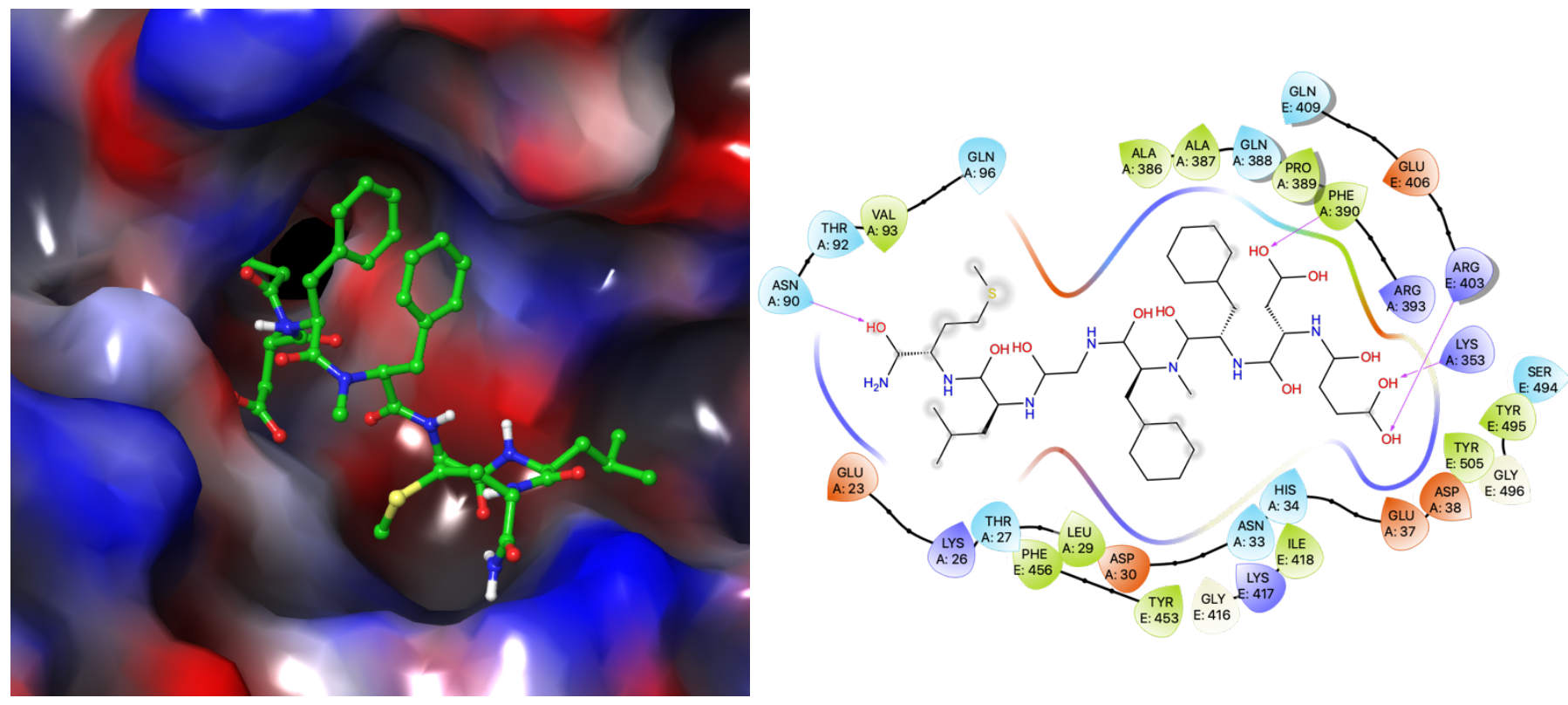